after a 6-day fast weighed $1600 \mathrm{~g}$. The animal was killed and no glycogen whatever was found in the liver.

These results show in a most marked way the glycogenetic properties of the carbohydrates in the litchi nut.

New Haven, Cons.

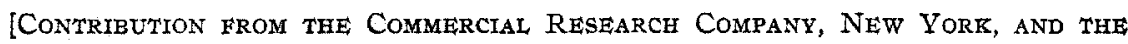
Melion Institute, Pitrsburgh.]

\title{
THE ACTION OF CONCENTRATED SULFURIC ACID ON OLE- FINS, WITH PARTICULAR REFERENCE TO THE REFINING OF PETROLEUM DISTILLATES.
}

BY BENJAMIN T, BroOKS AND IRWIN HUMPFREY,

Received February 21, 1918.

The original object of the investigation discussed in the following paper was to throw some light on the reactions involved in the refining of petroleum distillates, as ordinarily carried out in petroleum refineries. We were at first somewhat handicapped by the fact that previous work on the behavior of the olefins to conc. sulfuric acid was practically limited to the first 4 members of the series, ethylene, propylene, butylene and the amylenes. The present contribution, we feel, does little more than open up the subject. However, certain facts seem amply demonstrated, and some of these facts vary widely from those to be expected from the commonly accepted theories.

The recent extensive development of cracking processes for the manufacture of light petroleum distillates from heavier oils has emphasized the desirability of studying the reactions involved in refining such light oils. Petroleum distillates have been refined almost exclusively by treating with conc. sulfuric acid since the very beginning of the petroleum industry; in fact Benjamin Silliman advocated such a procedure in his famous report made in 1855 . The industry has apparently been quite content to accept the results of this operation, inasmuch as products so refined are generally acceptable to the users and no better refining method has, up to date, found general acceptance.

Although the action of dil. sulfuric acid, about $5 \%$ by volume, on a few olefins of the terpene series has been studied, a general investigation of the action of this, or other mineral acids on olefines has never been made; particularly is this true of the concentrated acids. The theory which has found practically universal acceptance in the petroleum industry is that the olefins occurring in petroleum distillates are polymerized by the acid to tars, form so-called "sulfo acids," and are completely removed from the oils so refined. That this assumption is wrong and that the so-called quantitative method of removing olefins by sulfuric acid gives misleading results will be brought out in the following 
pages. ${ }^{1}$ Indeed, $\mathrm{Nef}^{2}$ claimed that butylene and the higher olefin homologs' were quantitatively converted into polymers by strong sulfuric acid at $0^{\circ}$, while propylene remained dissolved in the acid as propyl sulfuric acid, and employed a quantitative method of separation of mixtures of these simpler substances, which was based on this idea. On the other hand, Wischnegradsky ${ }^{3}$ claimed to have obtained large yields of fusel oil by the action of cold conc. sulfuric acid on "amylene" and isolated the alcohol by diluting the acid layer with water, thus precipitating an oil consisting, in part, of an amyl alcohol. In view of the general confusion of ideas on the subject, and the lack of definite data on the behavior of olefins of different constitutions to conc. sulfuric acid, it has seemed necessary to attack the problem along broad lines, and, instead of first attempting an analytical study of the "acid oils" obtained in refinery practice, we first investigated the behavior of synthetic unsaturated hydrocarbons of definite purity and known constitution.

Since the more theoretical phases of the question are inextricably bound up with the practical side, it has seemed necessary to embody the whole of our findings and the discussion of them in a single paper.

\section{Theoretical Considerations.}

The Principal Results of the Action of Sulfuric Acid on Olefins are Polymerization, the Formation of Secondary and Tertiary Alcohols and Mono- and Dialkyl Esters of Sulfuric Acid. None of the Simple or Mono-olefins Studied Yield Tars with Conc. Sulfuric Acids at $15^{\circ}$.- We find that the relative importance of the above noted effects varies widely and depends primarily upon the constitution and molecular weight of the various substances, the concentration of the acid, and time. We are able to confirm the surmise of Michael and Brunel ${ }^{4}$ that in the aliphatic hydrocarbon series the tendency to form alkyl sulfuric esters and alcohols decreases with increasing molecular weight, this result appearing to be maximum with the amylenes and hexenes.

Michael and Brunel showed that isobutene $\left(\mathrm{CH}_{3}\right)_{2} \mathrm{C}=\mathrm{CH}_{2}$ is rapidly and completely dissolved by sulfuric acid, $63 \% \mathrm{H}_{2} \mathrm{SO}_{4}$, at $\mathrm{I} 7^{\circ}$. Also, tetramethyl ethylene $\left(\mathrm{CH}_{3}\right)_{2} \mathrm{C}=\mathrm{C}\left(\mathrm{CH}_{3}\right)_{2}$ reacts readily and completely with $77 \%$ acid at ordinary temperatures, but not as rapidly as the amylene $\left(\mathrm{CH}_{3}\right)_{2} \mathrm{C}=\mathrm{C}_{\mathrm{CH}_{3}}^{\mathrm{H}}$ Of the 2 amylenes $\left.\underset{\mathrm{CH}_{3}}{\mathrm{CH}_{3}}\right\rangle \mathrm{CHCH}=\mathrm{CH}_{2}$ and

${ }^{1}$ It should be pointed out that in the original method for determining olefins, which was proposed by Krämer and Böttcher, fuming sulfuric acid was stipulated, but Worstall (Am. Chem. J., 20, 664 (1898)), has pointed out, and it is a matter of common experience, that fuming sulfuric acid will attack saturated hydrocarbons.

2 Ann., 318, 26 (I90I).

Ibid., 190, 328 (1877).

4 Am. Chem. J., 4x, 118 (1909). 


\section{$\mathrm{C}_{2} \mathrm{H}_{5}$ $\mathrm{CH}_{3}$ \\ $\mathrm{C}=\mathrm{CH}_{2}$, the latter dissolves more readily in $66 \%$ acid. Michael}

and Brunel did not differentiate between the formation of alcohols and sulfuric esters, nor between unchanged hydrocarbons and polymers, but speak only of the hydrocarbons going into solution. In this connection it should be pointed out that with relatively dilute acids practically complete hydration to alcohols can occur without noticeable absorption, as in the commercial process for the manufacture of terpineol. Results very closely parallel to these have been noted by others in the case of the additive power of the amylenes and the halogen acids. ${ }^{1}$

As regards the effect of the constitution of the olefins on their reactivity to sulfuric acid, the following can be said: The substitution for the hydrogen of ethylene groups, which impart a strongly electronegative character, results in decreased reactivity to sulfuric acid. Thus we find that cinnamic and fumaric acids are not appreciably acted upon by $95 \%$ sulfuric acid at ordinary temperatures; and similarly dichloroethylene is acted upon only very slowly under the same conditions. Allyl bromide is also more stable toward conc. sulfuric acid than is propylene. ${ }^{2}$ On the other hand we find that tetramethylethylene is more reactive toward the acid than is its isomer, $\alpha$-hexene, which finds an explanation in the fact that the unsaturated group $>\mathrm{C}=\mathrm{C}<$ in $\alpha$-hexene has 3 of its valences taken up by hydrogen, while in tetramethylethylene these are replaced by the more strongly electropositive methyl groups. From this standpoint the greater reactivity of amylene, butylene and propylene as compared with ethylene is also readily explained. The behavior of the olefins of still greater molecular weight, however, is difficult to explain. Why they should be quite stable, as compared with the amylenes and hexenes, is not apparent, nor has any explanation suggested itself to ws as to why $\gamma$-ethyl- $\beta$-pentene should yield $72 \%$ alcohol and $12 \%$ polymers and $\alpha$-methyl- $\beta$-undecene give $97 \%$ polymers and only a trace of alcohol, since their structures are quite similar.<smiles>CC=C(CC)CC</smiles><smiles>CC(C)=Cc1ccccc1</smiles>

In the same way the known differences in the behavior of vinyl acetic acid $\mathrm{H}_{2} \mathrm{C}=\mathrm{CH} . \mathrm{CH}_{2} \mathrm{CO}_{2} \mathrm{H}$ and its isomer $\mathrm{H}_{2} \mathrm{C}=\mathrm{C}_{\mathrm{CO}_{2} \mathrm{H}}^{\mathrm{CH}_{3}}$ are difficult to explain. With $5 \%$ sulfuric acid, the former yields solid crotonic acid while the latter gives a polymerization product.

${ }^{1}$ Butlerow, Ann., 189, 5 I (1877); Ber., 12, 1483 (1879); Wischnegradsky, Ibid., 190, 35 I (1878); Eitekow, Ibid., Io, 707 (1877); Konowalow, Ibid., I3, 2395 (I880).

${ }^{2}$ Cf. Michael, Ber., 39, 2785 (1906). 
The tendency of the olefins and substituted ethylenes to react with sulfuric acid is distinctly less than their tendency to combine directly with bromine. Thus, cinnamic and fumaric acids, mentioned above, both readily yield dibromides, as is well known. ${ }^{1}$

Styrene, cinnamic alcohol, cinnamic aldehyde, eugenol, isoeugenol and safrol are very energetically polymerized by $85 \%$ sulfuric acid at $0^{\circ}$. The polymers in these cases were hard resins and no other products were isolated. Allyl alcohol reacts energetically with $60 \%$ acid to form the ordinary allyl hydrogen sulfate, the ethylene group not being affected to any appreciable extent.

With Increasing Molecular Weight, the Tendency is toward Polymerization.-Thus, the duodecene studied gave the dipolymer almost quantitatively. We have observed no instance of ring formation. In other words, when polymerization occurs through the influence of the acid, the polymer or polymers still contain at least one double bond and these unsaturated hydrocarbons of high molecular weight, $i$. e., the polymers, are much more stable toward sulfuric acid than the parent olefins. This is contrary to the popular idea, although this behavior is closely parallel to the observation of Kondakow, ${ }^{2}$ who studied the addition of hydrogen chloride to isobutene and its polymers. This relatively greater stability of the polymers toward sulfuric acid has the result that the more viscous heavier polymers are found not in the acid sludge, but, to a large degree, in the oil layer, or the refined oils of the petroleum refiner.

It has generally been assumed that the viscous petroleum oils, of the lubricating oil type, consist exclusively of naphthenes and polynaphthenes. The analyses of such oils, freed from paraffin, indicate the empirical formulas $\mathrm{C}_{n} \mathrm{H}_{2 n}$ and $\mathrm{C}_{n} \mathrm{H}_{2 n-2}$, and since they have undergone at least one treatment with sulfuric acid, such an assumption would seem superficially plausible. But, as we have shown, olefin hydrocarbons of large molecular weight are also viscous oils and are quite stable toward ordinary conc. sulfuric acid. The dipolymer $\mathrm{C}_{24} \mathrm{H}_{48}$ with one double bond of the duodecene mentioned above has a viscosity equal to light machine oil and the polymers of the unsaturated hydrocarbons prepared from cetyl alcohol and myricyl alcohol are quite viscous oils, very nearly. identical in their common physical properties with lubricating oils of corresponding molecular weight. That unsaturated hydrocarbons have considerably

${ }^{1}$ Bauer and Moser, Ber., 37, 3317 (1904), have called attention to the fact that certain ethylene derivatives which contain strongly electronegative substituent groups do not react with bromine, for example,<smiles>CCCCC(CCC)=C(CC)CCCC(Br)C(Br)CCCCC(=O)C(C)=C(C)C(=O)O</smiles>

${ }^{2} J$. prakt. Chem., [2] 54, 449 (1896). 
higher viscosities than the corresponding saturated hydrocarbons, has been shown by Dunstan and Hilditch. ${ }^{1}$

That the iodine numbers of refined lubricating oils indicate relaively very large percentages of unsaturated hydrocarbons has been generally ignored. An iodine number of 12 , in the case of a medium heavy lubricating oil, corresponds roughly to a mono-olefin content of $20 \%$. The idea that the iodine numbers can be so interpreted has usually been rejected, evidently owing to the prevailing opinion that olefins of large molecular weight are, like turpentine, energetically polymerized to tars. Since we have found that the higher open-chain olefin hydrocarbons and their polymers, are relatively stable toward sulfuric acid, we are of the opinion that the iodine numbers of some refined hibricating oils really indicate relatively large percentages of unsaturated hydrocarbons in such oils. ${ }^{2}$

\section{Theory of the Addition of Water to Olefins by Dilute and Con- centrated Acids.}

It has heretofore been supposed, and for good reasons, that when an alcohol is formed by the action of sulfuric acid upon an olefin that an ester of sulfuric acid is first formed, which is then hydrolyzed by water after the manner of the hydrolysis of ethyl hydrogen sulfate. Although these sulfuric acid esters can be hydrolyzed, as by boiling with water, we find abundant evidence that alcohols are formed at low temperatures, in the presence of sulfuric acid, without the intermediate formation of sulfuric esters of the known type. Thus, when the simpler alkenes, such as the amylenes, hexenes, or heptenes, are carefully treated with $85 \%$ sulfuric acid at temperatures not above $15^{\circ}$ and the resulting clear, ambercolored acid solution is slowly added to shaved ice, there is immediately precipitated a pale yellow oil containing, as its chief constituent, the free alcohol corresponding to the original hydrocarbon. This does not increase in amount when the aqueous acid solution is permitted to stand at room temperature several days, although ordinarily 30 to $40 \%$ of the original hydrocarbon remains in solution as the acid sulfuric ester. In a number of these experiments the aqueous solution, separated from the alcohol layer, was thoroughly extracted with ether to remove traces of dissolved alcohol, and the dilute aqueous sulfuric ester solution slowly heated in an oil bath until the strong characteristic odor of these alcohols was perceptible. These experiments proved conclusively that the mono or acid esters of the amylenes, hexenes and heptenes are not appreciably hydrolyzed in 10 minutes at any temperature below $90^{\circ}$. 'T his is also in accord with our observation that aqueous solutions of the barium salts

1 Z. Elektrochem., x7, 922 (1911).

2It should be pointed out that the iodine or bromine absorption values of oils are reduced by polymerization, a dipolymer of a simple mono-olefin having one-half the iodine or bromine absorption number of the original olefin. 
of these acid esters can be gently evaporated at about $40^{\circ}$ without decomposition. The only measurements of the rate of hydrolysis of such esters which have been made appear to be those of Linhart, ${ }^{1}$ who showed that a dilute solution of ethyl sodium sulfate was $16 \%$ hydrolyzed in 8 days at $60^{\circ}$.

On treating a mixture of hexenes with $100 \%$ sulfuric acid or with pure benzene sulfonic acid, no alcohols are formed. Also in comparative experiments, larger yields of alcohol were obtained with $85 \%$ than with $94 \%$ sulfuric acid. In other words, the water which is present in the reaction mixture, not the water in the subsequently diluted solution, enters into the reaction.

To account for the fact just mentioned, two theories have occurred to us which may lead to further information along these lines. One was suggested by the fact that the water in relatively concentrated sulfuric acid solutions is not present as such, but is combined, forming one or more of the well-known series of so-called hydrates. The best known perhaps is the monohydrate, the structure of which is probably that of orthosulfuric acid.

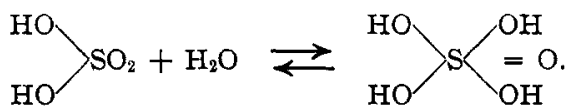

It is certain that esters of these 2 acids would have quite different degrees of stability and quite different rates of hydrolysis. All that can be said with certainty is that the ordinary esters $\mathrm{RCH}_{2}$ are relatively

$\mathrm{R}_{1} \mathrm{CHOSO} \mathrm{O}_{3} \mathrm{H}$

quite stable in aqueous solution. The orthosulfuric esters have not been isolated as such, but certain of the basic sulfates have been regarded as derived from it, as<smiles></smiles>

This theory readily explains the fact that the alcohol is not present as such before diluting with water. The free alcohol, if present, should dissolve in an immiscible solvent such as chloroform, which, we find, is not the case.

We have also sought an explanation of the observed facts in the somewhat close analogies between the behavior of olefins toward conc. sulfuric acid and toward zinc chloride. Anhydrous zinc and aluminum chlorides form well characterized addition products with unsaturated hydrocarbons. ${ }^{2}$ The compounds with zinc chloride react with water to

I Am. J. Sci., 35, 283 (1913).

2 Kondakow, $J$. prakt. Chem., [2] 48, 472 (1893); [2] 54, 447, 454 (1896); Henderson, This JournaL, 38, 1382 (I916); Gangloff and Henderson, Ibid., 39, 1420 (1917). 
give, in part, alcohols. The analogy is made more complete by the fact that the oil precipitated by pouring an apparently clear sulfuric acidolefin solution into water or cracked ice, often contains a considerable proportion of the original olefin, or one of its isomers. ${ }^{1}$ It should be pointed out, however, that the isolation of the so-called addition compounds with zine chloride and aluminum chloride, likewise the well-known mercury ethanol compounds, is particularly easy, well-defined crystalline compounds being formed. With the sulfuric acid solutions, in contrast, we have been unable to isolate any such addition product. The cryoscopic method so successfully employed by Kendall is not applicable in this case. We endeavored to get indirect evidence in this manner by selecting a crystalline acid which has marked reactivity toward olefins, but little polymerizing action, $i . e$, trichloroacetic acid, and the solid olefin hydrocarbon camphene. However, freezing-point curves of mixtures of these two substances gave no indication of the formation of an addition product.

Closely connected with the alcohol formation is the mechanism of the polymerization. Previous work throws practically no light on this phase of the strbject. Certainly from what is known, no generalizations can be drawn. The only case where the constitution of the zinc chloride or sulfuric acid polymer has been studied is that of isobutene and its dipolymer, ${ }^{2}$<smiles>CCC(C)(C)C=C(C)C</smiles>

The work of Harries on the ozonide degradation products of catalytically polymerized isoprene, or "isoprene rubber," indicates that in this case combination occurs exclusively through the $\alpha$-carbon atoms of the groups $\mathrm{RCH}=\mathrm{CH}_{2}$. We have nothing to add to the theory of polymerization by means of sulfuric acid except the observation that the polymers, in the cases studied by us, contain one double bond. In other words, ring formation with the mono-olefins has not been observed to occur.

The preparation of unsaturated hydrocarbons of definite constitution and free from isomers presented a little difficulty, inasmuch as we desired to investigate examples of the 5 possible types of substituted ethylenes,

(I).<smiles>[R]C=C</smiles>

(II).<smiles>[R]C([R4])=C</smiles>

(III).<smiles>[R]C=C[R1]</smiles>

${ }^{1}$ Examples of isomerization by means of sulfuric acid are fairly numerous; for example $\left(\mathrm{CH}_{3}\right)_{2} \mathrm{CH} . \mathrm{CH}=\mathrm{CH}_{2}$ to $\left(\mathrm{CH}_{3}\right)_{2} \mathrm{C}=\mathrm{C}\left\langle\mathrm{CH}_{\mathrm{H}}\right.$, isopulegone to pulegone, alpha pinene to terpinene, etc

2 Kondakow, Loc. cit. 
(IV).<smiles>[R]C=C([R])[R4]</smiles>

(V).<smiles>[R]C([R4])=C([R1])[R]</smiles>

In several instances this was accomplished by removal of water from alcohols or hydriodic acid from alkyl iodides having certain symmetrical structures, for instance the alcohol triethyl carbinol and the iodide $\mathrm{CH}_{3} \mathrm{CH}_{2} \mathrm{CH}_{2} \mathrm{CHI}$. $\mathrm{CH}_{2} \mathrm{CH}_{2} \mathrm{CH}_{3}$.

The normal $\alpha$-olefins were prepared by a simple adaptation of the synthesis of allyl derivatives of benzol, which has been described by Tiffeneau. ${ }^{1}$ We find that allyl bromide reacts smoothly with the magnesium alkyl bromides to give $\alpha$-olefins. ${ }^{2}$

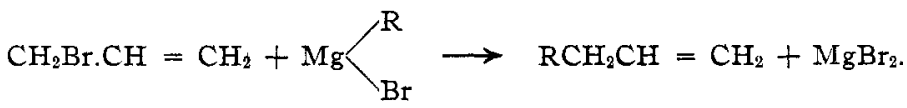

In view of the fact that some of the $\alpha$-olefins prepared in this way possess physical properties differing considerably from the properties attributed to these hydrocarbons in the literature we have reviewed the older methods of preparing them and conclude that the present instance is the first time certain of these substances have been isolated in a pure state.

Hydrocarbons of this type seemed to be of considerable importance in connection with the behavior of the unsaturated petroleum oils since Brochet ${ }^{3}$ claimed to have identified $\alpha$-hexene and $\alpha$-pentene in the light distillate from bog head coal, and $\mathrm{Haber}^{4}$ has claimed that paraffin hydrocarbons dissociate under the influence of heat, mainly to give methane and an $\alpha$-olefin, as in the reaction

$$
\mathrm{RCH}_{2} \mathrm{CH}_{2} \mathrm{CH}_{3} \rightarrow \mathrm{RCH}=\mathrm{CH}_{2}+\mathrm{CH}_{4} \text {. }
$$

Thus Haber showed that between $600^{\circ}$ and $800^{\circ}$ hexane decomposed mainly to methane and an amylene and wrote the above equation to express this change, although he did not examine the structure of the resulting amylene. In view of the well-known tendency of $\alpha$-olefins to rearrange, ${ }^{5}$ we regard the assumption that the unsaturated hydro-

Compt. rend., 139, $48 \mathrm{I}$ (1904).

${ }^{2}$ Although this reaction proceeds very smoothly, we have noted that magnesium allyl bromide reacts with the alkyl bromides, as propyl bromide, only very slowly, the yields of hydrocarbon being very poor.

${ }^{3}$ Bull. soc. chim. phys., -[3] 7, 566 (1892).

${ }^{4}$ Ber., 29, 269 I (1896).

6 The rearrangement of methylbutene ${ }_{\mathrm{CH}_{8}}^{\mathrm{CH}_{3}} \mathrm{CHCH}=\mathrm{CH}_{2}$ to trimethylethylene $\mathrm{CH}_{3}>\mathrm{C}=\mathrm{CH} . \mathrm{CH}_{3}$ is well established. Also Wurtz (Ann., 127, 55 (1863); 148, 13 (1868)) attempted to prepare $\alpha$-olefins by reacting upon the zinc alkyls with allyl 
carbons of cracked petroleum oils are of this type, to be entirely unwarranted and extremely improbable.

We have also employed the bromo-ester condensation method of Reformatsky and Wallach, as, for example the synthesis of $\alpha$-octene from oenanthol, but this has proven of little value as a preparative method in the present instance since the unsaturated acids do not readily lose carbon dioxide.

As regards the formation of unsaturated hydrocarbons by decomposing secondary and tertiary alcohols, we have found that distillation of the alcohol to which a trace of iodine has been added gives very much better yields in many instances than the older methods. Thus triethylcarbinol readily yields the hydrocarbon $\left(\mathrm{C}_{2} \mathrm{H}_{5}\right)_{2} \mathrm{C}=\mathrm{CHCH}_{3}$ and the tertiary atcohol $\mathrm{CH}_{3}\left(\mathrm{CH}_{2}\right)_{8} \mathrm{C} . \mathrm{OH}\left(\mathrm{CH}_{3}\right)_{2}$ gives a good yield of the hydrocarbon $\mathrm{CH}_{3}\left(\mathrm{CH}_{2}\right)_{7} \mathrm{CH}=\mathrm{C}_{\mathrm{CH}_{3}}^{\mathrm{CH}_{3}}$, the constitution of which we were able to confirm by the formation of acetone by oxidation.

In view of the old process of manufacturing hydroxystearic acid from oleic acid by treating with conc. sulfuric acid in the cold, followed by steam hydrolysis, we thought that perhaps the higher straight-chain olefins of the type $\mathrm{H}^{\mathrm{R}}=\mathrm{C}{ }_{\mathrm{H}}^{\mathrm{R}_{1}}$ could be converted into wax-like alcohols, but the unsaturated hydrocarbons prepared from cetyl and myricyl alcohols react normally, that is, like other unsaturated hydrocarbons of ro or more carbon atoms, giving polymers and small percentages only of soluble sulfuric esters. No trace of solid substance could be separated from the products by freezing. Nevertheless, we consider the preparation of solid waxes from the higher boiling unsaturated hydrocarbons of petroleum to be a possibility.

We find that saturated aqueous solutions of sulfur dioxide are entirely without action on the simple olefins at ordinary temperature. After 8o hours' shaking a petroleum hexene mixture with saturated aqueous sulfur dioxide the olefin was quantitatively recovered unchanged. Diolefins are known to give resinous polymers which contain sulfur.

\section{Experimental.}

$\beta$-Methyl- $\alpha$-butane, $\mathrm{C}_{2} \mathrm{H}_{5} \mathrm{C} \mathrm{CH}_{2}$-A small amount of this amylene, boiling point $33^{-35^{\circ}}$, made by decomposition with removal of water from iodide, but when zinc ethyl is treated with allyl iodide, only $\beta$-pentene is obtained. The success of our method with the magnesium alkyl bromides is readily explained by the fact that the magnesium halides are not nearly so reactive toward olefins as are the zinc halides. 
dimethylethyl carbinol, dissolved completely in 2 volumes of $85 \%$ sulfuric acid in a few minutes at $10^{\circ}$. A yield of $45 \%$ of the theory of the original tertiary alcohol was liberated by diluting with ice water. No polymers were formed.

$$
\beta \text {-Methyl- } \alpha \text {-pentene, }{ }_{{ }_{3}}^{\mathrm{CH}_{3} \mathrm{H}_{7}}>\mathrm{C}=\mathrm{CH}_{2} \text {. This hydrocarbon, boiling }
$$

point $64-66^{\circ}$, was prepared by the action of bromoacetic ester and zinc on methylpropyl ketone and decomposition of the resulting oxy-ester and acid. ${ }^{1}$ Since the hydrocarbon is evidently new, we regret that the small quantity of it available and the limited time at our disposal prevented us confirming the constitution inferred from the method employed in its preparation. The methylpropyl ketone used was isolated from acetone oil by repeated fractional distillation. The condensation with the ester proceeds smoothly, giving nearly theoretical yields of the oxyester, but on saponifying this ester with sodium methylate in methyl alcohol almost complete hydrolysis occurs, probably after the manner indicated by Wallach for other similar esters, to give the original ketone. From 200 g. of the ketone there was finally isolated only $12 \mathrm{~g}$. of the hexene. From this small quantity of the olefin only part of the desired data was obtained. On treating at $10^{\circ}$ with 2 volumes of $85 \%$ sulfuric acid the oil lost $55 \%$ of its volume by solution. On diluting with ice water $4.5 \mathrm{~g}$. of light yellow oil were obtained, having the strong camphor-like odor common to the tertiary alcohols, indicating the presence of the alcohol $\mathrm{C}_{3} \mathrm{H}_{7} \mathrm{C} . \mathrm{OH}\left(\mathrm{CH}_{3}\right)_{2}$.

Petroleum Hexene Mixture.-The material used in this experiment was a mixture of the olefins resulting from the action of alcoholic potassium hydroxide on monochlorohexanes and had a boiling-point range of $55^{-6} 3^{\circ}$; specific gravity, 0.7045 . To $200 \mathrm{~g}$. of the hydrocarbon, I.25 moles of sulfuric acid, sp. gr. r.84, were added with cooling, the temperature being permitted to rise to $40^{\circ}$. The usual amber-colored viscous solution was formed. After standing half an hour the mixture was treated in the usual manner. The washed, supernatant oil, light yellow in color, measured $\mathrm{I}_{52} \mathrm{cc}$., sp. gr. $0.77 \mathrm{O}$, weight II 7 g. Refluxing with aniline for 3 hours, according to the method of Heusler, ${ }^{2}$ yielded aniline sulfate, determined in the aqueous washings as barium sulfate, equivalent

I We find that the condensation of methylpropyl ketone and bromoacetic ester in presence of zinc goes almost violently if the reaction materials are thoroughly dried. From $212 \mathrm{~g}$. methylpropyl ketone we obtained $356 \mathrm{~g}$. of the $\beta$-oxy- $\beta$-methylpentane- $\alpha$ carbonic acid ethylester, a thick, viscous syrup, first described by Semlianizin ( $J$. prakt. Chem., [2] 23, 267 (188I)). But very poor yields were obtained on saponifying with sodium methylate in methyl alcohol. This fact and the cost of the materials required render the Reformatsky synthesis of little practical value as a preparative method.

2 Ber., 28, 488, 498 (1895). 
to $0.55 \mathrm{~g}$. of sulfuric acid, but the decomposition of the sulfuric esters was incomplete, as shown by the evolution of sulfur dioxide when the oil was distilled.

Three fractional distillations of the oil readily resolved it into the following:

\begin{tabular}{|c|c|c|c|c|}
\hline & & B. p. & $\%$. & Sp. gr. \\
\hline I. & Unchanged hydrocarbon. . & $60-75^{\circ}$ & 21.0 & \\
\hline II. & Intermediate fraction. & $75^{-190^{\circ}}$ & 6.0 & 0.764 \\
\hline III. & Dipolymer................ & $190-200^{\circ}$ & 35.0 & 0.784 \\
\hline IV. & Residue, higher polymers above......... & $200^{\circ}$ & .36 .0 & 0.836 \\
\hline & Iross. ........... & & 3.0 & \\
\hline
\end{tabular}

The dipolymer was unsaturated to cold dilute potassium permanganate and bromine in acetic acid.

The acid layer on diluting yielded $58.0 \mathrm{~g}$. of oil, sp. gr. 0.872 . This was distilled with steam until the camphor-like odor had disappeared, yielding $24 \mathrm{~g}$. of oil, sp. gr. $0.827,80 \%$ of which boiled at $130-140^{\circ}$, indicating a hexyl alcohol. Phenylisocyanate gave a phenylurethane melting at $235^{\circ}$. The aqueous acid layer was treated with barium carbonate and, on very gentle evaporation of the filtrate, the barium hexyl sulfate was obtained as a very soluble, somewhat gummy crystalline salt. After washing with a little alcohol, the salt analyzed as follows:

Calc. for $\left(\mathrm{C}_{6} \mathrm{H}_{13} \mathrm{OSO}_{3}\right)_{2} \mathrm{Ba}: \mathrm{Ba}, 27.8$. Found: 28.1

Another quantity of hexene, made from crude monochlorohexane, ${ }^{1}$ was treated successively with $85 \%$ and $95 \%$ sulfuric acid, the results indicating the increasing stability of the polymers to the acid. On treating $280 \mathrm{~g}$. of the hexene, sp. gr. 0.7045 , b. p. $55^{-6} 3^{\circ}$, with $400 \mathrm{~g} .85 \%$ of sulfuric acid, we recovered $\mathrm{I} 64 \mathrm{~g}$. oil, or $58.6 \%$ of the original oil. From the mixture of polymers we isolated by distilling at $26 \mathrm{~mm}$. pressure 2 fractions, $100-5_{50}^{\circ}, 57 \mathrm{~g}$., sp. gr. 0.8180 ; and $\mathrm{r}_{50}-190^{\circ}$, $5 \mathrm{I} \mathrm{g}$., sp. gr. $0.844^{2}$. These fractions were then treated with equal volumes of more concentrated acid, sp. gr. I.84. The loss to the stronger acid was $31 \%$ for the lower boiling and $28 \%$ for the higher boiling fraction. Redistilling at $26 \mathrm{~mm}$. showed that only $14 \%$ had been converted into still more complex polymers boiling above $190^{\circ}$ at this pressure.

$\alpha$-Hexene.-As noted in the first part of this paper, the majority of the normal $\alpha$-olefins as described in the literature are in reality isomers of the olefins, or mixtures. Thus $\alpha$-hexene is usually described as boiling at $68-70^{\circ}$ and its history is readily traced to the early work of Morgan ${ }^{2}$ and Schlorlemmer, who prepared the hydrocarbon by removal of hydro-

i We attempted to prepare the hexyl iodides from the chlorides by means of the well-known reaction with sodium iodide in acetone, but with very poor results. At ordinary temperatures very little reaction results and on warming abundant separation of iodine occurs.

2Ann., 177, 305 (1875). 
chloric acid from a chlorinated hexane fraction, the latter having been obtained from petroleum. A close examination of Morgan's work indicates that his hydrocarbon was probably $\beta$-hexene. Zelinsky and Przewalsky ${ }^{1}$ heated $n$-hexyl iodide with quinoline and obtained a liquid mixture boiling from $35^{\circ}$ to $67^{\circ}$. On oxidizing the fraction boiling from $63.5-65^{\circ}$ they obtained a mixture of butyric and valeric acids, showing that the hexene was a mixture of the $\alpha$-and $\beta$-isomers. That $\alpha$-olefins, if originally formed in a pyrogenetic process, tend to rearrange is indicated also by the formation of a hexene, probably $\beta$-, from normal heptyl alcohol by passing over finely divided nickel at $220^{\circ}$. The hydrocarbon so obtained boiled at $67.7-68.1^{\circ}$ and was regarded by Van Beresteyn ${ }^{2}$ as $\alpha$ hexene, expressing its formation as follows:

$$
\mathrm{CH}_{3}\left(\mathrm{CH}_{2}\right)_{3} \mathrm{CH}_{2} \mathrm{CH}_{2} \mathrm{CH}_{2} \mathrm{OH} \text {. } \rightarrow \mathrm{CH}_{3}\left(\mathrm{CH}_{2}\right)_{3} \mathrm{CH}=\mathrm{CH}_{2}+\mathrm{CO}+{ }_{2} \mathrm{H}_{2}
$$

However, von Braun ${ }^{3}$ obtained a hexene by gently heating $n$-hexyl trimethyl ammonium hydroxide, which showed a boiling point of $62-63^{\circ}$ and which he regarded as the true $\alpha$-hexene, although he was unable to prove the constitution of it, owing to the small quantity obtained, $\mathrm{r} .5 \mathrm{~g}$. Since the method of preparation employed by us readily yielded the pure $\alpha$-hexene, free from isomers, we were able to prove its constitution. Its physical properties are as follows:

$$
\text { B. p. } 756 \mathrm{~mm} .60 .5-61.5^{\circ} ; n_{\mathrm{D}}^{200}, 1.3821 ; \mathrm{d}_{20}^{20}, 0.6830 \text {. }
$$

The following method of preparation indicates the procedure followed with but little variation in the preparation of the $\alpha$-olefins: Normal propyl bromide, $85 \mathrm{~g}$., was added to $18 \mathrm{~g}$. magnesium turnings in $500 \mathrm{cc}$. of ether. After the magnesium compound had formed the reaction mixture was chilled and $68 \mathrm{~g}$. allyl bromide in $60 \mathrm{cc}$. ether was gradually added during a period of 24 hours. The ether solution was poured from the residue of magnesium bromide to avoid any possibility of isomerization by warming with the magnesium salt, and most of the ether distilled. Ether was completely removed from the remainder by washing out several times with large volumes of water, and the hydrocarbon distilled. Only 3 cc. were obtained boiling below $60.5^{\circ}$. The yield was 34 g.; b. p.,

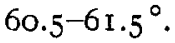

The constitution of the hydrocarbon was shown by a method which has not been employed heretofore, so far as we know, in determining constitution. ${ }^{4}$ The modification of the older methods which we have employed consists in the addition of hypochlorous acid to form the chloro-

1 Chem. Zentr., 79, II, I854 (1908).

2 Ibid., I9I1, II, IOI7.

'Ann., 382, 22 (1911).

- Oxidation of the olefin by chromic acid can not be employed in this case owing to the fact that rearrangement of the $\alpha$-olefin to the $\beta$-isomer has been observed with iso- $\alpha$-pentene. 
hydrine (both the $\alpha$-chloro, $\beta$-oxy- and the $\alpha$-oxy- $\beta$-chloro derivatives are probably formed) and the conversion of the chlorohydrine into the glycol by warming in a dilute aqueous solution of sodium bicarbonate. The yield of glycol is much superior to that obtained by the old permanganate oxidation method. ${ }^{1}$ The chlorohydrines are readily made by shaking the hydrocarbon with an aqueous solution of hypochlorous acid made by adding boric acid to a cold solution of bleaching powder.

Alpha hexene, $52 \mathrm{~g}$., was slowly added to $100 \mathrm{cc} .85 \%$ sulfuric acid at $15^{\circ}$ during a period of 20 minutes. The hydrocarbon dissolved completely to a clear, riscous, amber-colored solution. The solution was poured into 4 volumes of water and cracked ice. With this amount of water the large supernatant layer consisted of hexyl sulfuric acid and free alcohol. On adding about 6 volumes of cold water to this supernatant layer, the hexyl sulfuric acid passed into solution and the free hexyl alcohol layer separated. This alcohol or "acid oil" layer was washed thoroughly with water. The aqueous solution was extracted with ether to remove all dissolved free hexyl alcohol, obtaining a total of $28.0 \mathrm{~g}$. oil, having $\mathrm{d}_{20^{\circ}}^{20}$, 0.823 . The alcohol distilled principally at $134-138^{\circ}$ and acetylated readily in acetic anhydride to the secondary hexyl acetate boiling point, $154-158^{\circ}$.

The aqueous solutions containing the hexyl sulfuric acid (as such it proved to be) were combined and treated with an excess of barium carbonate, filtered with suction, and the aqueous solutions gently evaporated during about 48 hours at $355^{\prime \prime} 40^{\circ}$. The dry crystalline barium salt weighed $44 \mathrm{~g}$. It is very soluble in water, the concentrated aqueous solutions having a marked syrupy consistency.

Calc. for $\left.\left(\mathrm{C}_{6} \mathrm{H}_{18} \mathrm{OSO}\right)_{3}\right)_{2} \mathrm{Ba}: \mathrm{Ba}, 27.4 \mathrm{O}$. Found: 27.23 .

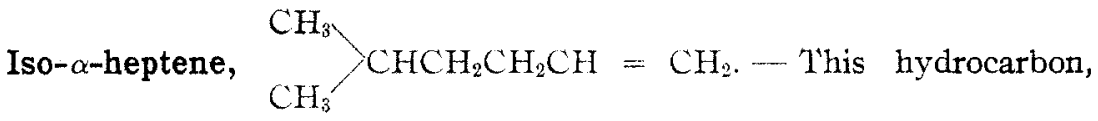

which is new, was made by acting upon magnesium isobutyl bromide with allyl bromide in the manner already described for $\alpha$ olefins. This heptene boils at $85^{-86^{\circ}}$ and has $\mathrm{d}_{15^{\circ}}^{15^{\circ}}, 0.7160$. By treating ${ }_{5} \mathrm{~g}$. of the hydrocarbon with $25 \mathrm{~g}$. of $85 \%$ sulfuric acid, we obtained $7.3 \mathrm{~g}$. polymers, $\mathrm{d}_{15^{\circ}}^{15^{\circ}}, 0.7933$, which proved to consist mostly of the dipolymer, as indicated by the boiling point $220-224^{\circ}$, at which temperature about $5 \mathrm{~g}$. of the oil distilled.

$\gamma$-Heptene.-This hydrocarbon was made by starting with the symmetrical alcohol dipropyl carbinol, converting this into the iodide and removing hydriodic acid by caustic alkali in the usual manner. ${ }^{2}$ It will be

${ }^{1}$ A separate paper on this method is in preparation.

2 Splitting off water from this alcohol by refluxing and distillation with iodine is too slow in this case to be of practical value. $90 \mathrm{~g}$. of the alcohol and $0.3 \mathrm{~g}$. iodine gave only $0.5 \mathrm{~g}$. water in 5 hours at $145^{\circ}$. 
seen that owing to the symmetry of this compound, simple removal of hydriodic acid and barring molecular rearrangement, only the olefin $\gamma$-heptene should result. After purification, the boiling point was found to be $93^{-}-95^{\circ}$ (previously noted $95.5^{\circ}$ ) and $\mathrm{d}_{20^{\circ}}^{20}$, o.7020.

A quantity of the heptene, $68 \mathrm{~g}$., was slowly added during 30 minutes to $200 \mathrm{~g}$. of $85 \%$ sulfuric acid, the reaction mixture being kept chilled to $15^{\circ}$. The oil dissolved completely. The clear, viscous amber-colored solution was added to 4 volumes of ice and water and the supernatant layer of free alcohol and heptyl sulfuric acid and water weighed I $88 \mathrm{~g}$.; calculated for the monoheptyl ester, $136 \mathrm{~g}$. On diluting this sulfuric ester layer with 6 volumes of ice water there was obtained, after the usual washing with water and extracting the aqueous acid solutions, $42.0 \mathrm{~g}$. alcohol which, on distillation under $26 \mathrm{~mm}$. pressure, boiled mostly at $75-77^{\circ}$. The alcohol acetylates quantitatively with acetic anhydride. The water-soluble barium salt, isolated as described above, weighed $8 \mathrm{r} .0 \mathrm{~g}$.

Calc. for $\left(\mathrm{C}_{7} \mathrm{H}_{15} \mathrm{OSO}_{3}\right)_{2} \mathrm{Ba}: \mathrm{Ba}, 26.0$. Found: 26.29 .

It is worthy of note that with both $\alpha$-hexene and $\gamma$-heptene no polymers were formed.

$$
\gamma \text {-Ethyl- } \beta \text {-pentene, } \quad \begin{aligned}
& \mathrm{C}_{2} \mathrm{H}_{5} \\
& \mathrm{C}_{2} \mathrm{H}_{5}
\end{aligned}>\mathrm{C}=\mathrm{CH}-\mathrm{CH}_{3} \text {.--This hydrocarbon, }
$$

boiling point $97-98^{\circ}$, was made by the dehydration of triethyl carbinol, ${ }^{1}$ and, owing to the symmetry of this alcohol, the derived olefin is exceptionally pure. This heptene was treated at $0^{\circ}$ with sulfuric acid, sp. gr. I.84. The behavior of this olefin is markedly different from the duodecene described below and it is noteworthy that the 2 hydrocarbons possess similar constitutions. To IO2 $\mathrm{g}$. of the hydrocarbon I20 g. of the acid were slowly added with vigorous mechanical agitation. After standing about half an hour, $2 \mathrm{I} \mathrm{g}$. of clear supernatant oil were removed and treated again with an equal volume of sulfuric acid, sp. gr. 1.84. After treatment, the residual oil was removed, washed and distilled, obtaining:

\begin{tabular}{|c|c|c|c|}
\hline Fraction. & B. p. & Volume, cc. & Sp. gr. \\
\hline$I \ldots \ldots \ldots \ldots \ldots$ & to $210^{\circ}$ & 3 & $\cdots$ \\
\hline II $\ldots \ldots \ldots \ldots \ldots \ldots$ & $210-220^{\circ}$ & $7 \cdot 5$ & 0.793 dipolymer \\
\hline $\operatorname{III} \ldots \ldots \ldots \ldots \ldots \ldots \ldots$ & $220-250^{\circ}$ & 4.0 & $\cdots$ \\
\hline Residue............... & $\ldots$ & I. 5 & $\ldots$ \\
\hline
\end{tabular}

The viscous amber-colored sulfuric acid solution was run into cracked ice and 82 g. of crude alcohol, sp. gr. 0.820 , were obtained. On washing with dilute alkali, $7 \mathrm{~g}$. were removed (see below). The crude alcohol thus obtained was light yellow in color and smelled strongly like the original tertiary alcohol. Distillation gave the following:

${ }^{1}$ Saytzen, J. prakt. Chem., [2] 57, 38 (I898). 


\begin{tabular}{|c|c|c|c|}
\hline Fraction. & B. p. & Wt. g. & Sp.gr. \\
\hline I. . & $90-$ II $^{\circ}$ & 20.5 & 0.773 \\
\hline II $\ldots \ldots \ldots \ldots \ldots \ldots \ldots$ & $115-130^{\circ}$ & 26.3 & 0.786 \\
\hline III. ................... & $130-150^{\circ}$ & 9.6 & 0.789 \\
\hline $\mathrm{IV} \ldots \ldots \ldots \ldots \ldots \ldots \ldots$ & $150-190^{\circ}$ & 1.7 & \\
\hline$\vee \ldots \ldots \ldots \ldots \ldots \ldots \ldots$ & $190-220^{\circ}$ & 6.9 & 0.862 \\
\hline Residue $\ldots \ldots \ldots \ldots \ldots$ & $\ldots$ & 9.5 & 0.896 \\
\hline
\end{tabular}

By redistilling 3 times, the alcohol Fractions II and III were almost completely decomposed, with splitting off of water to the unsaturated hydrocarbon. Of the 2 alcohols whose formation is possible, $\left(\mathrm{C}_{2} \mathrm{H}_{5}\right)_{2} \mathrm{C}<\mathrm{CH}_{2} \mathrm{CH}_{3}$ and $\left(\mathrm{C}_{2} \mathrm{H}_{5}\right)_{2} \mathrm{CHCHOH} . \mathrm{CH}_{3}$, the former only is known, and the instability of the alcohol formed in this case indicates that it is the tertiary one. That this tertiary alcohol should be formed in this case in conc. sulfuric acid is noteworthy as indicating that tertiary alcohols are formed rather than secondary. In the same way the $\alpha$-olefins form secondary not primary alcohols.

It was assumed that the aqueous acid solution contained heptyl sulfuric ester. Accordingly, it was further diluted to 0.5 liter and thoroughly extracted with ether until all odor of the camphor-like tertiary alcohol was removed. Half of the solution was distilled with steam and $3.0 \mathrm{~g}$. of oil ubtained, having the characteristic odor of the tertiary alcohol. The wher half of the solution was further diluted and the barium salt made in the usual manner, obtaining, by very gentle evaporation of the filtered aqueous solution at about $50^{\circ}, 6.5 \mathrm{~g}$. of the salt. Analysis showed:

Calc. for $\left(\mathrm{C}_{7} \mathrm{H}_{15} \mathrm{OSO}_{3}\right)_{2} \mathrm{Ba}: \mathrm{Ba}, 26.0$. Found: 27.6 .

The somewhat high per cent. of barium found is undoubtedly due to slight decomposition of the salt.

Tetramethyl Ethylene,<smiles>CCCCCCCCCCCCCCCCC(C)=C(C)C</smiles>

by decomposition, with removal of water, of dimethyl isopropyl carbinol by means of acetic anhydride. Three fractional distillations of the resulting hydrocarbon gave a very pure product boiling at $73^{-7} 74^{\circ} \mathrm{d}_{20^{\circ}}^{20^{\circ}}$, 0.7075 .

A quantity of the olefin, $46.5 \mathrm{~g}$., was slowly added to $150 \mathrm{~g}$. of $85 \%$ sulfuric acid at $0^{\circ}$ during one hour's time. Solution is markedly more rapid and energetic than in the case of $\alpha$-hexene. The crystals of monohydrated sulfuric acid gradually disappeared and the hydrocarbon dissolved completely. On standing for one hour, the temperature rising to $15^{\circ}$, a colorless oil layer weighing $37.6 \mathrm{~g} ., \mathrm{d}_{20^{\circ}}^{20^{\circ}}, 0.775 \mathrm{O}$, separated. Fractional distillation of this oil showed its principal constituent to be the dipolymer, 

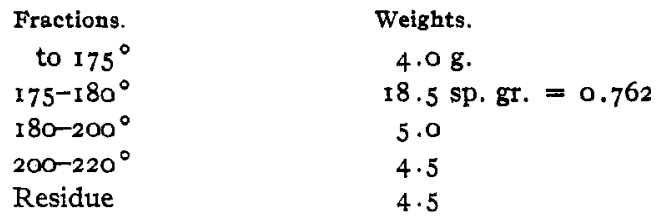

On diluting the acid layer with water and cracked ice only $1.6 \mathrm{~g}$. of alcohol were obtained (including that recovered by ether extraction) which possessed the strong camphor-like odor of the original carbinol. The soluble barium salts, recovered in the usual way, weighed $20.2 \mathrm{~g}$. (accounting for about $7.1 \mathrm{~g}$. of the original olefin). 'This salt proved to be noticeably more unstable than the salts derived from secondary alcohols, as from $\alpha$-hexene, $\gamma$-heptene and the like. It decomposed slowly on standing at room temperature and analysis showed a percentage of barium somewhat higher than required by the theory, a result readily explained by the instability of the salt.

\section{Calc. for $\mathrm{Ba}\left(\mathrm{OSO}_{3} \mathrm{C}_{6} \mathrm{H}_{38}\right)_{2}: \mathrm{Ba}, 27.4$. Found: 28.6.}

Sulfuric Acid, $100 \% \mathrm{H}_{2} \mathrm{SO}_{4}$, on Hexenes.- The hexenes employed in this experiment were not pure and were prepared from a monochlorohexane fraction derived from a petroleum hexane fraction. The crude hexenes boiled at $58-70^{\circ}$ and had a specific gravity of 0.700 . To $200 \mathrm{~g}$. of the acid $70 \mathrm{~g}$. of the hexene were slowly added at $-10^{\circ}$. A total of $62 \mathrm{~g}$. was recovered as polymers and these distilled over a wide range up to $250^{\circ}$ under $20 \mathrm{~mm}$. pressure. Polymerization evidently proceeds much farther with acid of this concentration, the last fraction being a heavy viscous oil, sp. gr. 0.90I. We were surprised that the amount of water-soluble alkyl sulfuric acid was so low, only $3.2 \mathrm{~g}$. of soluble barium salt being obtained. Considerable oxidation was noted, even at this low temperature, as indicated by the evolution of sulfur dioxide and the formation of $12 \%$ of tarry matter not distilling up to $250^{\circ}$ at $20 \mathrm{~mm}$. pressure.

The absence of alcohols in the products of this experiment is significant, as discussed in the first part of this paper. A small amount of "acid oil" which separated on diluting the acid with cracked ice was examined for alcohols by acetylating gently. One gram of the oil so treated required $39 \mathrm{mg}$. caustic potash and I g. hexyl acetate requires $389 \mathrm{mg}$. potash. Heating the acid oil liberated sulfur dioxide at the rate of $0.029 \mathrm{~g}$. sulfur dioxide per gram oil, thus partly accounting for the small saponification value of the acetylated sample.

A more conclusive result regarding the non-formation of alcohols when water-free acids are employed was obtained by the use of benzene sulfonic acid, thus avoiding the oxidation and energetic polymerization of the pure anhydrous sulfuric acid. 
Benzenesulfonic Acid and $\gamma$-Heptene.--In view of the formation of dialkyl esters of sulfuric acid by the action of sulfuric acid on an excess of the olefins, it seemed to us quite probable that benzenesulfonic acid would behave in a similar way. To $25 \mathrm{~g}$. of $\gamma$-heptene, prepared as described above, an excess of pure crystalline benzenesulfonic acid was added at room temperature. Solution with evolution of heat took place and after standing about 2 hours, the excess of the sulfonic acid was removed from the resulting heavy oil by washing with water and dil. sodium bicarbonate solution. The resulting ester, $\mathrm{d}_{20^{\circ}}^{20^{\circ}}, 0.979$, could not be distilled at $20 \mathrm{~mm}$. without decomposition, sulfur dioxide being evolved. Saponification of $1.922 \mathrm{~g}$. required $393 \mathrm{mg}$. caustic potash, or $204.5 \mathrm{mg}$. per gram; the benzenesulfonic ester requires theoretically $254 \mathrm{mg}$. The crude ester evidently contained a little unchanged heptene, but the strong odor of the secondary heptyl alcohol, very noticeable even when small traces are present, was totally absent. Saponification of the ester with aqueous caustic soda readily yields heptyl alcohol, b. p. $134^{-1}-16^{\circ}$ and probably contains both dipropylcarbinol and ethylbutylcarbinol.

$\alpha$-Octene.--Heptylaldehyde, purified from commercial oenanthol, was condensed with bromoaceticester and zinc to the $\beta$-oxypelargonic acid ethylester in dry benzol according to Wallach's modification of the Reformatsky reaction. The oxy-ester was saponified by sodium methylate in 20 volumes of methyl alcohol. The oxy-acid was made by Wagner ${ }^{1}$ in another way, and the product described by him as melting at $48-5 \mathrm{I}^{\circ}$ probably was impure, since the oxy-acid obtained by us, recrystallized from ether-ligroin, melted sharply at $58.5^{\circ}$. The yields were poor. From $228 \mathrm{~g}$. of heptylaldehyde we obtained I I $4 \mathrm{~g}$. of the oxy-acid. This was heated with acetic anhydride, as recommended by Wallach, giving $82 \mathrm{~g}$. of the unsaturated acid. We find that this $\alpha$-octene $\alpha$-carbonic acid is relatively stable. It was described by Fittig ${ }^{2}$ simply as an oil. We find that it distills with very little decomposition at $220-223^{\circ}$.

To $52 \mathrm{cc}$. of the octene, b. p. 122-124 $4^{\circ}$, sp. gr. 0.7240 , was added $50 \mathrm{cc}$. of $85 \%$ sulfuric acid, $\mathrm{H}_{2} \mathrm{SO}_{4}$, maintaining the mixture at $20^{\circ}$. Very little discoloration and very little heating effect were noted. The oil layer, $38 \mathrm{cc}$, very faintly yellow, after washing until neutral, had the specific gravity 0.854 . On attempting to distil this oil, it quickly blackened and gave off sulfur dioxide, suddenly and with such violence that the whole mass frothed over into the receiver. This was carefully redistilled, obtaining $32 \mathrm{cc}$, b. p. $122-124^{\circ}$. We hope to repeat this experiment and determine the per cent. of the sulfur dioxide, in view of these unexpected results.

The acid layer yielded only $2.5 \mathrm{cc}$. of oil, having the odor of secondary 1 Ber., 27, 2436 (1894).

2Ann., 227, 80 (1885). 
octyl alcohol. This was dried and treated with phenylisocyanate, the phenylurethane, recrystallized from methyl alcohol, melting at $238^{\circ}$.

With $96 \%$ sulfuric acid, a greater percentage of polymers was formed, and, as in the other cases studied, largely the dipolymer. From $30 \mathrm{cc}$. of the octene, $24 \mathrm{cc}$. "insoluble" oil were recovered, which on distillation gave:

I. Unchanged hydrocarbon. ...........

$\begin{array}{rc}\text { Boiling point. } & \text { Per cent. } \\ 120-125^{\circ} & 16 \\ 125^{-1} 195^{\circ} & 9 \\ 195^{-2} 30^{\circ} & 32 \\ \text { above } 230^{\circ} & 42\end{array}$

Although the boiling point of the $\alpha$-octene, made as indicated above by heating $\alpha$-octene- $\alpha$-carbonic acid, agrees with the boiling point of $\alpha$ octene described in the literature, we are inclined to believe that this socalled $\alpha$-octene may be the $\beta$-olefin, since, as already pointed out, heat causes the olefins to rearrange. The method of preparation for this octene described in the literature, namely, decomposition of secondary octyl iodide, also indicates that the known hydrocarbon of this boiling point may be the $\beta$-compound.

$\alpha$-Isooctene.--This hydrocarbon, which is new, was made with a very satisfactory yield by the condensation of magnesium isoamyl bromide and allyl bromide in the manner discussed above. Its physical properties are as follows:

$$
\text { B. p., III-II }{ }^{\circ} ; \mathrm{d}_{4}^{200}, 0.7 \text { I } 25 ; n_{\mathrm{D}}^{200^{\circ}}, 1.3986
$$

Sixty grams of the hydrocarbon were slowly treated with 225 g. of $85 \%$ sulfuric acid at $15^{\circ}$. The clear yellow acid layer was poured into cracked ice, thus separating $9.0 \mathrm{~g}$. of the secondary alcohol, $\beta$-oxy- $\zeta$-methyl heptane. Owing to the small quantity of this alcohol available, the constitution tentatively ascribed to it was not verified. It acetylates readily in acetic anhydride, yielding an acetate having a pleasant fruity odor, boiling at $190-193^{\circ}$.

The oil layer separated from the acid weighed 48 g.; sp. gr., o.80o. The oil, light yellow in color, was distilled at $16 \mathrm{~mm}$., giving $8.1 \%$ unchanged octene, $53.3 \%$ dipolymer $\mathrm{C}_{16} \mathrm{H}_{32}$; sp. gr. 0.798 , and b. p. II2I $4^{\circ}$ at $16 \mathrm{~mm}$. The impure higher polymers, $28.6 \%$, had a specific gravity of 0.804 . The dipolymer showed a bromine absorption, in acetic acid solution, of 74 ; calculated for one double bond in $\mathrm{C}_{16} \mathrm{H}_{32}=7 \mathrm{I}$. Only r.5 g. soluble barium octyl sulfate were recovered from the acid solutions.

The relatively large amount of polymers and small amount of alcohol and octyl sulfuric esters, as compared with the behavior of $\alpha$-hexene, is worthy of note.

$$
\beta \text {-Methyl- } \beta \text {-undecene, } \mathrm{C}_{12} \mathrm{H}_{24}, \quad \mathrm{C}_{8} \mathrm{H}_{17} \mathrm{CH}=\mathrm{C} C_{\mathrm{CH}_{8}}^{\mathrm{CH}_{3}} \cdot \text { - Methylnonyl }
$$


ketone was isolated from oil of rue by means of the sodium bisulfite compotund.' By acting upon the ketone with magnesium methyl iodide, the tertiary alcohol was obtained and on distilling this alcohol with a trace of iodine, a nearly theoretical yield of the unsaturated hydrocarbon was obtained. Since this hydrocarbon is new, we give its constants as follows.

B. p. at $75^{2} \mathrm{~mm} ., 210-211.5^{\circ} . \quad \mathrm{D}_{4}^{200^{\circ}}, 0.7590 ; n_{\mathrm{D}}^{200}, 1.4270 \mathrm{MR}$; calc. for $\mathrm{C}_{12} \mathrm{H}_{24}$ : 56.93. Found: $56.5 \mathrm{r}$. Bromine number, calc. for $\mathrm{C}_{12} \mathrm{H}_{24}: 95.0$. Found: $95 . \mathrm{n}$.

That the constitution of the hydrocarbon is in fact that noted above was shown by oxidizing with chromic acid solution in the usual manner, distilling with steam and proving the presence of acetone in the distillate by the iodoform reaction and the formation of dibenzylidene acetone; m. p., ir I ${ }^{\circ}$.

A quantity of the hydrocarbon weighing $79 \mathrm{~g}$. (IO4 cc.) was treated slowly with $\mathrm{r} 30 \mathrm{~g}$. of $85 \%$ sulfuric acid at $20^{\circ}$. A viscous, light yellow emulsion was obtained which, however, quickly separated on standing a few minutes. The mixture was vigorously shaken for 20 minutes, but after standing ro minutes longer there occurred a complete separation into a clear straw-colored acid layer and a water-white, viscous oil layer, the latter measuring $95 \mathrm{cc}$. After washing with water and dil. alkali and drying, this "insoluble oil" weighed 75.5 g.; sp. gr., 0.799 . The increase in specific gravity is quite marked. The oil was then heated to $200^{\circ}$ to decompose any sulfuric acid esters present, but only $0.028 \mathrm{~g}$. sulfur dioxide was obtained and the oil was only very slightly discolored. It was then distilled under $28 \mathrm{~mm}$. pressure and the following fractions were obtained:

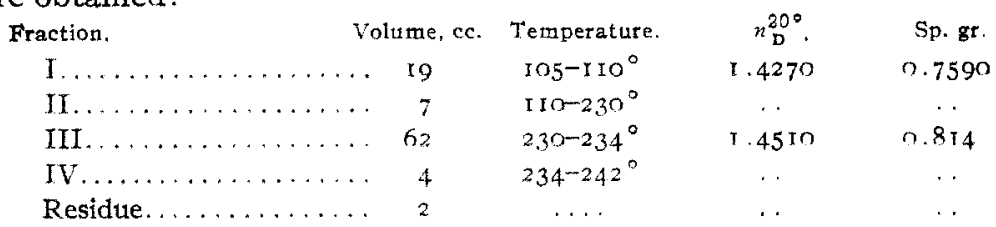

These results were quite surprising in showing that the original hydrocarbon had been converted into the dipolymer and practically no higher polymers had been formed. The polymerized oil, even before distillation, was water-white in color and, moreover, this effect had been produced accompanied by a loss to the sulfuric acid of but $4.4 \%$ by weight. These results were so entirely at variance with the generally accepted notions of the behavior of petroleum olefins to sulfuric acid that the experiment was repeated, employing sulfuric acid of $96 \%$ concentration. In the above experiment, the loss to the acid was so small that it was not at-

1 Previous workers have stated that this ketone reacts only very slowly and with difficulty with sodium bisulfite solution. We find that if the bisulfite solution contains 20 to $30 \%$ of ethyl alcohol, the reaction can be completed in a few minutes. 
tempted to isolate the acid oil, in fact only a few drops of oily substance, having an odor suggestive of the higher alcohols, were obtained on diluting the acid layer with water.

The dipolymer $\mathrm{C}_{24} \mathrm{H}_{48}$ is also an unsaturated hydrocarbon as was indicated by its behavior toward cold alcoholic potassium permanganate and toward a solution of bromine in acetic acid. Titration of $3 \mathrm{cc}$. of the dipolymer in acetic acid, with a solution of bromine in acetic acid, gave a bromine number of 43 ; calc. for $\mathrm{C}_{24} \mathrm{H}_{48}: 47.5$.

Concentrated sulfuric acid, sp. gr. I.84, gives practically the same results as the $85 \%$ acid. Owing to the fact that only a small quantity of the original hydrocarbon was available, the experiment could not be made as complete as the one above. However, on treating $\mathrm{I} 5 \mathrm{cc}$. of the oil at $20^{\circ}$, the loss, after agitating thoroughly for 20 minutes, was I. $5 \mathrm{cc}$., or about 10\% by volume. The supernatant oil was very faintly yellow, and on distillation proved to consist of the dipolymer to the extent of about $85 \%$.

Hexadecene from Spermaceti.-A hexadecene was made from purified spermaceti, essentially cetyl palmitate, by making use of the well-known method of destructive distillation of palmitic acid esters. The crude product of the destructive distillation was chilled to remove most of the free palmitic acid, washed thoroughly with hot dil. caustic soda and distilled in vacuo. The crude hexadecene had the following properties:

B. p. $130-150^{\circ}$ at $\mathrm{J} 8 \mathrm{~mm}$; $\mathrm{d}_{20}^{20}, 0.8850$; bromine number (in acetic acid solution), 68.1.

In view of the method of preparation of this hydrocarbon it probably contains little or none of the $\alpha$-hexadecane which would normally be first formed, but one or more isomers of the $\alpha$-olefin.

With $85 \%$ sulfuric acid this mixture of unsaturated hydrocarbons remains practically unchanged after thorough agitation at ordinary temperatures. From $160 \mathrm{~g}$. of the oil we recovered $148 \mathrm{~g}$. unchanged oil distilling within the original range above noted, Io $\mathrm{g}$. higher boiling residue which naturally consisted partly of unchanged material, and $2 \mathrm{~g}$. loss. This loss occurred largely in handling. On diluting the acid solution only a slight turbidity was noted and no separation of acid oil or tar.

With more concentrated sulfuric acid, sp. gr. I.84, considerable polymerization occurred. On agitating the oil and acid at room temperature, about $22^{\circ}$, the mixture warmed slightly, but no tar formation, charring or blackening was observed. The acid layer which separated on standing gave no acid oil on diluting with ice water. From $86 \mathrm{~g}$. of the crude hexadecene we obtained $84 \mathrm{~g}$. of a very viscous oil which, on fractionating at $18 \mathrm{~mm}$., yielded the following: I $30-155^{\circ}, 25.0 \%$, considered as unchanged oil; $155^{-320^{\circ}}, 52.4 \%$ mostly dipolymer $\mathrm{C}_{32} \mathrm{H}_{64}$; residue above $320^{\circ}$, $19 \mathrm{~g}$. or $22.6 \%$. This residue was particularly interesting from the 
petroleum technologists' point of view, as it had a viscosity equal to very heavy cylinder oil of about I 6 to I 8 degrees Engler. It seems certain, therefore, from the results found, particularly in this case and with the duodecene described above, that so far as the action of sulfuric acid on olefins is concerned, the refined oils should show greater viscosities than the original distillates, but this difference is usually more than counterbalanced by removal of other substances, in some cases asphaltic material. That refining of crude kerosenes increases their flash points, is well known and the theory which had already been advanced to explain the change, is supported by the results we find.

The marked differences in their behavior to sulfuric acid, between the hydrocarbons of I 2 to 16 carbon atoms and the unsaturated fatty acids, such as oleic acid, is difficult to account for. ${ }^{1}$

Menthene.-By slowly distilling menthol with ${ }_{\mathrm{r}} \%$ of iodine, a molecule of water is readily removed from the menthol, forming a menthene, b. p. $169-170^{\circ}, \mathrm{d}_{4}^{20^{\circ}} 0.8 \mathrm{II}$, and probably identical with the menthene of this boiling point studied by Wallach. ${ }^{2}$ A quantity, measuring I I9 $\mathrm{cc}$. of the hydrocarbon was treated with Ioo cc. of $85 \%$ sulfuric acid, and thoroughly shaken for 20 minutes. After standing until the 2 layers had become clear, the supernatant oil measured Ior cc. and after washing and drying had a specific gravity of 0.867 at $20^{\circ} / 4^{\circ}$. This oil was fractionated, obtaining $35 \%$ unchanged menthene and $55 \%$ dimenthene $\mathrm{C}_{28} \mathrm{H}_{36}$, b. p. 310-3I $5^{\circ}$, sp. gr. $0.899, n_{\mathrm{D}}^{20^{\circ}}$ I. 4795 . Like the other dipolymers previously obtained, the dimenthene was unsaturated but the bromine or iodine absorption numbers could not be obtained, owing to decomposition of the halogen derivatives and discoloration of the acetic acid solution.

On adding the sulfuric acid solution to cold water, $12.5 \mathrm{~g}$. of oil separated, smelling strongly of menthol. Distillation of this oil gave a small

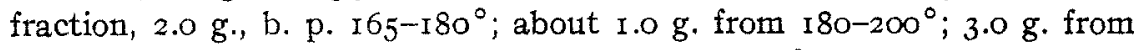
$200-215^{\circ}$; and $5 \mathrm{~g}$. residue. The fraction $200-215^{\circ}$ had a strong odor of menthol, but no crystals separated from it on cooling at $-15^{\circ}$.

Effect of Time on Yield of Polymers.- The yield of alcohol and polymers obtained in Expts. 2 and 4, Table IV, indicates that on standing, the yield of polymers increases at the expense of alcohol. This is well shown by the behavior of secondary octyl alcohol, $\beta$-oxy- $n$-octane. To $50 \mathrm{~g}$. of the alcohol, roo g. conc. sulfuric acid, sp. gr. 1.84, were gradually

1 According to unpublished results of this laboratory, the unsaturated fatty acids are much easier hydrogenated than are the unsaturated hydrocarbons. Our first surmise was that the petroleun olefins contained traces of sulfur compounds, which poisoned the catalyst, but a mixture of cottonseed oil and highly unsaturated kerosene, iodine number 55.2 , purified by distillation over fine copper oxide yielded a semi-solid mixture of solid hydrogenated cottonseed oil and the kerosene practically unchanged.

inn., 300, 282 (1898). 
added during to minutes, keeping the mixture cooled to $20^{\circ}$. The solution, which was originally clear, but dark brown in color, became turbid, and oil separated, the volume of which was read at frequent intervals. The solution became quite dark in color but no tarry matter was formed. The supernatant layer of oil was light amber in color.

Formation of Polymers from SeCONDary OCtYL AlCohol.

Time, minutes.

I5

30

45

60

85

IO5

I 35
$\%$ by volume.

8.0

17.0

40.0

50.0

52.0

56.0

62.0

On distillation the oil gave about $40 \%$ of the dipolymer $\mathrm{C}_{18} \mathrm{H}_{32}$, distilling at $275^{-285^{\circ}}$, the remainder consisting of slightly viscous higher polymers, probably the tripolymer $\mathrm{C}_{24} \mathrm{H}_{48}$.

r. Methyl- $\Delta_{1}$-cyclohexene.-Only a small quantity of this hydrocarbon was available. The oil, I5.6 g., having the b. p. $105^{-106^{\circ}}$ and $\mathrm{d}_{20^{\circ}}^{20}, 0.820$, was treated with $35 \mathrm{~g}$. of $85 \%$ sulfuric acid at $a^{\circ}$. The insoluble polymers weighed I I.5 g. and on redistillation $80 \%$ of this oil boiled at $255^{-260^{\circ}}$, $\mathrm{d}_{40^{\circ}}^{20^{\circ}} 0.906$, evidently consisting of the dipolymer $\mathrm{C}_{14} \mathrm{H}_{28}$. The acid layer on diluting with ice water yielded $4.0 \mathrm{~g}$. crude alcohol, having the mintlike odor of the tertiary alcohol methyl (I) cyclohexanol (I).

Cinnamic Acid.-We have found no reference to the addition of water to cinnamic acid by means of dil. sulfuric acid. We find that $85 \%$ and $96 \%$ sulfuric acid neither polymerizes or hydrates the substance. After thoroughly agitating the mixture and allowing to stand at $25^{\circ}$ for 24 hours, the solid material was filtered with suction, the acid filtrate diluted with water and extracted with ether. From Ioo g. of cinnamic acid there was obtained in this way about $2.0 \mathrm{~g}$. of substance which proved to be unchanged cinnamic acid. Also, fractional crystallization of the solid material gave no evidence of the presence of the lower melting hydroxy acids.

Dichloroethylene:-This substance reacts slowly at $20^{\circ}$ with $85 \%$ and with $96 \%$ sulfuric acid. On agitating equal volumes, $150 \mathrm{cc}$. of the substance and the acid, the acid layer becomes discolored and hydrogen chloride is evolved. After agitating the mixture half an hour, separating and washing as usual, the loss in volume of the dichloroethylene was $6 \%$. Distillation showed that no polymerization whatever had occurred.

The sulfuric acid solution was run into to volumes of cold water. A strong aldehyde odor was noticed. The aqueous solution was distilled with steam and the first $25 \mathrm{cc}$. of distillate examined. It smelled strongly of chloroacetaldehyde, reduced ammoniacal silver solution giving a mirror, 
and an oily precipitate with phenylhydrazine solution. The reaction is evidently as follows:<smiles>O=CC(Cl)C(O)C(Cl)CO[14C](Cl)Cl</smiles>

The Terpenes, $\alpha$ - and $\beta$-Pinene, Limonene and Myrcene.-- A quantity of ordinary turpentine was distilled, collecting the fraction $155^{-1} 59^{\circ}$. This was assumed to be largely ordinary or $\alpha$-pinene. As usually carried out, the reaction of conc. sulfuric acid and turpentine is so energetic that the temperature rapidly rises and oxidation with the separation of carbon, tar, sulfur dioxide, etc., occurs. However, at $0^{\circ}$ with $85 \%$ sulfuric acid, the reaction can be readily controlled and the reaction mixture maintained at this temperature. Under these conditions the principal reaction products are the dipolymer $\mathrm{C}_{20} \mathrm{H}_{32}$, distilling at $17 \mathrm{O}^{-1} 75^{\circ}$ under $15 \mathrm{~mm}$. pressure and the very viscous tripolymer. On distilling the forerunnings, a marked odor of borneol was noticed, but no crystals could be isolated. To $79 \mathrm{~g}$. of the pinene, b. p. $155^{-1} 59^{\circ}, \mathrm{d}_{4}^{20^{\circ}}$ o.8630, there was slowly added, at $0^{\circ}$ with vigorous stirring, $150 \mathrm{~g}$. acid. The reaction mixture was so viscous that it was allowed to stand several hours at about $5^{\circ}$ in order to separate the two liquids. In all $72 \mathrm{~g}$. oil were recovered, which on distillation at $15 \mathrm{~mm}$., resolved itself chiefly into the two fractions
$170-175^{\circ} \quad 32 \mathrm{~g}$.
$175^{-245^{\circ}} \quad 7 \mathrm{~g}$.
$245^{-260^{\circ}} \quad$ i $8 \mathrm{~g}$.
Sp. gr. 0.938 , dipolymer, $\mathrm{C}_{24} \mathrm{H}_{32}$
Intermediate
Probably tripolymer, $\mathrm{C}_{30} \mathrm{H}_{48}$, very viscous

In another experiment in which $72 \%$ sulfuric acid was employed at $25^{\circ}$, a yield of $62 \%$ of the dipolymer, b. p. $170-175^{\circ}$ at $15 \mathrm{~mm}$., was obtained.

A quantity of $\beta$-pinene ${ }^{1}$ behaved in an entirely similar manner. In these experiments we were unable to note any difference in the behavior of the two isomers, in other words, as between the $\Delta_{6}$ and $\Delta_{1(7)}$ structures.

From $250 \mathrm{~g}$. $\beta$-pinene we obtained $239 \mathrm{~g}$. liquid, sp. gr. 0.940 , by treating as above with $85 \%$ acid, which on distilling at $12 \mathrm{~mm}$. gave:

$\begin{array}{rrrrl}\text { B. p. } & \text { W. } & \text { Sp. gr. } & n_{\mathrm{D}}^{20} & \text { Product. } \\ 55^{\circ}-70^{\circ} & 21.5 & 0.85 \mathrm{I} & \mathrm{I} .4670 & \mathrm{C}_{10} \mathrm{H}_{16} \\ 70-165^{\circ} & 14.8 & 0.872 & 1.472 .5 & \text { Intermediate } \\ 165-171^{\circ} & 113.2 & 0.935 & 1.4838 & \mathrm{C}_{20} \mathrm{H}_{82} \\ 17 \mathrm{I}-285^{\circ} & 62.0 & 0.95 \mathrm{I} & \ldots & \text { Very viscous }\end{array}$

The further study of these dipolymers was not undertaken.

Limonene, isolated from sweet orange peel oil, behaved in a very similar manner to the pinenes. From I $85 \mathrm{~g}$. we obtained $174.5 \mathrm{~g}$. of the mixture of polymers, sp. gr. 0.934 , which on distilling at $\mathrm{I} 2 \mathrm{~mm}$. gave:

' Furnished to us through the kindness of Dr. A. W. Schorger of the Forest Products Laboratory. 


$\begin{array}{ccccc}\text { B. p. } & \text { Wt. } & \text { Sp. gx. } & n_{\mathrm{D}}^{20} . & \\ 60-167^{\circ} & 20.5 & 0.821 & 1.47 \mathrm{I} 8 & \text { Viscous, } \mathrm{C}_{20} \mathrm{H}_{82} \\ 167-172^{\circ} & 74.2 & 0.939 & 1.4828 & \\ 172-245^{\circ} & 26.0 & 0.945 & \cdots & \text { Very viscous, dries to touch by } \\ 245-260^{\circ} & 29.0 & 0.954 & \cdots & \text { air oxidation }\end{array}$

Myrcene was prepared by the decomposition of linalool with removal of water by distilling with a very small quantity of iodine. From $270 \mathrm{~g}$. linalool there were obtained nearly the theoretical quantity of water by slowly distilling with $3 \mathrm{~g}$. iodine during 2 hours. Fractional distillation gave 103 g. myrcene, b. p. $165^{-167^{\circ}}$; a small fraction, 24 g., b. p. $167^{-}$ $177^{\circ}$, consisting apparently of a mixture of myrcene and limonene; and about $143 \mathrm{~g}$. unchanged linalool and polymers. The reaction of myrcene with $85 \%$ sulfuric acid was so energetic at $o^{\circ}$ that we were unable to prevent tar formation, oxidation, carbonization, etc. In this respect its behavior is like the known behavior of cyclopentadiene and $\mathrm{cy}$ clohexadiene.

The freezingpoint curves for camphene and trichloroaceticacidare given in the accomp a n y ing figure. Trichloroacetic acid is $\mathrm{known}$ to be

Freezing-point curves, camphene and trichloroacetic acid.

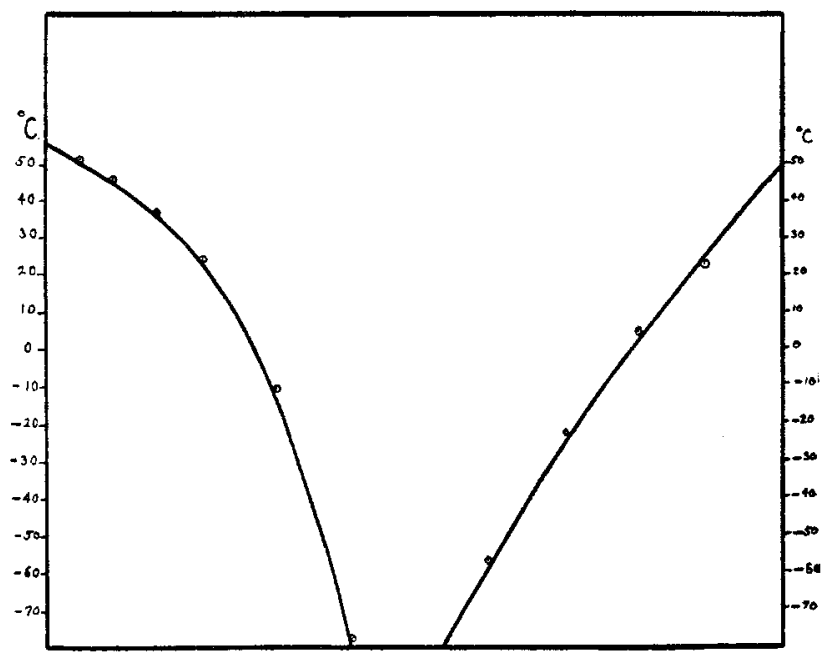

Trichloroacetic acid. Per cent.

Fig. 1 . somewhat reactive toward olefins, but no attempt is made here to review this behavior. ${ }^{1}$

The action of $85 \%$ sulfuric acid on styrene results only in the resinous polymer. No trace of either primary or secondary phenylethyl alcohol is formed, as the fragrant odor of both these alcohols is readily observed when present only in traces. From $23 \mathrm{~g}$. pure styrene with $25 \mathrm{~g}$. of the acid at $5^{\circ}$ we obtained only the polymer. No sulfuric esters were formed.

Both $96 \%$ and $85 \%$ conc. sulfuric acid are without action on fumaric acid. Ten grams fumaric acid were vigorously shaken with $25 \mathrm{~g}$. of $96 \%$ sulfuric acid at room temperature, the mixture poured into ice water and $9.8 \mathrm{~g}$.

1 Timofeev and Kravtzov, Chem. Abs., 9, 2896 (1915); II, 788 (1917). 
unchanged fumaric acid recovered. The filtrate was carefully examined for coumalic acid, but without result.

A New Decene, ${ }_{\mathrm{CH}_{3}}^{\mathrm{CH}_{3}}>\mathrm{CH} \cdot\left(\mathrm{CH}_{2}\right)_{4} \cdot \mathrm{CH}\left\langle\mathrm{CH}_{3}\right.$.- - In the preparation of iso- $\alpha$-octene, described above, there were obtained I $7 \mathrm{~g}$. of decene in a preparation in which $250 \mathrm{~g}$. isoamyl bromide were converted into the Grignard magnesium compound. Its formation is due to the decomposition of the isoamyl magnesium bromide after the manner common to the higher alkyl halides.

$\underset{\mathrm{CH}_{3}}{\mathrm{CH}_{3}}>\mathrm{CHCH}_{2} \mathrm{CH}_{2} \mathrm{MgBr}+\underset{\mathrm{CH}_{3}}{\stackrel{\mathrm{CH}_{3}}{>}}>\mathrm{CHCH}_{2} \mathrm{CH}_{2} \mathrm{Br} \longrightarrow$

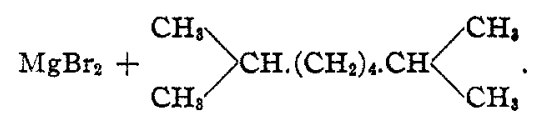

Its constitution was not proven, but inferred from the manner of its formation. Its constants are as follows:

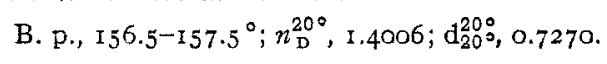

\section{Part II. The Action of Sulfuric Acid on Petroleum Distillates.}

General Discussion of the Refining Problem.-When petroleum oils are agitated with conc. sulfuric acid, a rise in temperature is commonly observed. In the case of low boiling, highly unsaturated oils, such as oil gas "drips" and many light oils rich in benzene, this may be sufficient to cause boiling, and in this case is invariably accompanied by the evolution of sulfur dioxide. With lubricating oils and with less highly cracked light oils, this rise in temperature is not so marked. After agitation, the emulsion is allowed to stand and a heavy viscous layer containing most of the sulfuric acid separates. When this heavy layer is run into water, an oil mixture is precipitated, which, in the case of the lower boiling petroleum distillates, is a yellow fluid oil having a very characteristic, sweetish odor, and which darkens rapidly on exposure to air. The more viscous distillates yield in this way a tarry "acid sludge." The customary refinery practice is to burn these acid oils and tars under the stills. The diluted acid is evaporated and concentrated for reuse, but organic matter continues to separate during the concentration and causes considerable loss of acid by reduction, accompanied by charring, and is a great source of trouble to the refiner.

Our investigation of mono-olefins as high as $\mathrm{C}_{24} \mathrm{H}_{48}$ in complexity, and including representatives of the 5 possible types, shows that tars are not formed by the action of ordinary conc. sulfuric acid on them at ordinary temperatures. On the other hand, tars are formed from highly unsaturated distillates, even the low boiling ones, which have been made by 
heating oils to very high temperatures, $600^{\circ}$ to $800^{\circ}$, as in the manufacture of oil gas. Such light oils are rich in benzene and its homologs. The tars formed on treating such oils are apparently due to the presence of diolefins. Acetylene homologs are not usually present. The unsaturated oils up to and including kerosene distillates made by cracking at lower temperatures, $400^{\circ}$ to $420^{\circ}$, as in pressure distillation of heavy oils, give fluid "acid oils" when treated with sulfuric acid.

It is a fact known to most refiners that on refining gasoline and kerosene, particularly the products made by cracking, the resulting refined products have higher specific gravities than the original oils, although if the refining operation consisted essentially of the removal of olefins, the refined product should be lighter than the original, as is, in fact, the case when the liquid sulfur dioxide method is employed. ${ }^{1}$ We have shown that when the refining is done in closed vessels, so as to preclude loss of the more volatile constituents by evaporation, the same change is noted and this is due primarily to the first of the following causes: The presence in the refined product of heavier polymers of the unsaturated hydrocarbons, originally present, as the conversion of duodecene $\mathrm{C}_{12} \mathrm{H}_{24}$, sp. gr. 0.759 , to the dipolymer $\mathrm{C}_{24} \mathrm{H}_{48}, \mathrm{sp}$. gr. 0.814 , and also to the presence in the refined product of dialkyl esters of sulfuric acid. These esters,<smiles>[R]OS(=O)(=O)O[R20]</smiles>
are, of course, neutral and are not removed by washing with aqueous alkalies. We have also shown that the proportion of these sulfuric esters in the refined products is roughly inversely proportional to the relative amount of sulfuric acid employed, as is readily apparent on considering the two equations
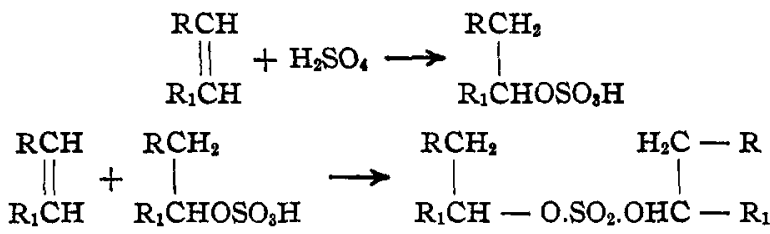

That saturated hydrocarbons are sulfonated by fuming sulfuric acid is well known from the work of Worstall, Markownikoff, and others. This question, however, is not part of the present problem. It has been claimed by $\mathrm{McKee}^{2}$ that saturated hydrocarbons may be sulfonated and that, for example, kerosene may be sulfonated by ordinary conc. sulfuric acid by vigorous shaking. We have never had in our possession any saturated hydrocarbons which would exhibit such behavior to ordinary sulfuric acid. Pure normal heptane, isolated from Pinus

${ }_{1}^{1}$ Schultz, Petroleum, 5, 205, 446 (1909).

2 Chem. Ztg., 36, 872 (1912). 
sabiniana, ${ }^{1}$ was absolutely unaffected by shaking with sulfuric acid, sp. gr. 1.84, at $25^{\circ}$ for 48 hours. Also, a sample of di-isopropyl ${ }^{2}$ was entirely unaffected when treated in the same manner. With fuming sulfuric acid, $15 \% \mathrm{SO}_{3}$, di-isopropyl lost $32.2 \%$ by volume on agitating for 35 minutes at $22^{\circ}$.

The aromatic hydrocarbons, which are invariably present in very small proportions, undoubtedly react to a slight extent to form true sulfonic acids, since the higher benzene homologs are very readily sulfonated and one of us has previously shown that the fluorescent substances in petroleum oils are readily sulfonated by ordinary sulfuric acid to give fluorescent, water-soluble sulfonic acids. ${ }^{3}$

It has previously been mentioned by one of $\mathrm{us}^{4}$ that the objectionable odor of gasoline obtained by pressure distillation is in part due to nitrogen bases. Since the present paper has to do primarily with olefins, we shall merely note here that, on gently heating a quantity of gasoline, made by pressure distillation of heavy Oklahoma fuel oil, with copper oxide, the nitrogen bases present combined with the oxide. The copper oxide compounds yield deep blue aqueous solutions and when the blue solution, or the copper oxide, was treated with alkali, a very strong odor suggestive of pyridine was noticed. Analysis of the copper oxide showed $3.4 \%$ nitrogen, or $19.1 \%$ calculated as pyridine. Such nitrogen bases naturally pass into the acid "sludge" layer on refining."

In an earlier paper, ${ }^{6}$ we noted that gasoline and kerosene which have

1 Furnished to us through the kindness of Dr. A. W. Schorger of the Forest Products Laboratory.

This hydrocarbon was prepared by the action of anhydrous aluminum chloride on paracymene. It is contained in the fraction boiling at $60-80^{\circ}$. The benzol present may readily be removed by nitrating, and the pure hexane may then be obtained, b. p. $56-58^{\circ}$.

${ }^{3}$ Brooks and Bacon, J. Ind. Eng. Chem., 6, 623 (1914).

4 Brooks, J. Frank. Inst., 180, 653 (1915).

5 On heating a mixture of lime and "acid sludge tar" from Oklahoma oil, ammonia was evolved. One kilo of the tar gave $0.51 \mathrm{~g}$. of ammonia, whose identity was confirmed by analysis of the chloroplatinate. It is to be expected that most of the sulfates of ammonia and the simpler bases will remain in solution on diluting with water and would not be found to any great extent in the tars or acid oils. Certain crude petroleums are markedly rich in nitrogen bases. We have noticed that when heavy Mexican oil was subjected to slow cracking distillation, ammonia was evolved toward the end of the process to such extent that it was a great annoyance to persons in the vicinity of the still. Cf. Mabery and Hudson, Am. Chem. J., 25, 253 (I gor).

- Brooks, Loc. cit. Unsaturated or cracked gasolines may be very satisiactorily refined by employing only a relatively small quantity of sulfuric acid followed by redistillation. In other words, it is not necessary entirely to polymerize or remove the olefins present to so improve the crude gasoline in respect to odor and color to be quite equal to good commercial standards. Samples of highly unsaturated and foul-smelling gasolines which we have puritied in a manner such as to leave their content of olefins undiminished, as by digestion with fine copper oxide, metallic sodium, etc., have held 
been refined in the usual way and subsequently redistilled, retained its water-white character and agreeable odor much better than such products treated in the same way, but not redistilled, and that this difference is particularly marked in the case of the oils derived by heat cracking processes. We have been able to show the presence in such oils of nentral esters of sulfuric acid which are retained by the refined oils, even after washing with alkali until neutral. They are rapidly decomposed at $\mathrm{I}_{4} 0^{\circ}$, or higher temperatures, but decomposition also takes place slowly at ordinary temperatures and such oils darken in color on standing and there separates a small proportion of a brown, viscous layer containing a little free acid and considerable resinous matter. When heated, as in distillation, these esters are decomposed with charring and evolution of sulfur dioxide.

The Refining of Cracked Gasolines.-Very early in our work we attempted to refine gasolines made by cracking heavy oils at temperatures

Tabi,E I.-EFfFet of Refining on the Specific Gravity of Unsaturated

\begin{tabular}{|c|c|c|c|}
\hline \multirow[b]{2}{*}{ No. } & \multicolumn{2}{|c|}{ Specific gravity. } & \\
\hline & $\begin{array}{l}\text { Original } \\
\text { gasoline. }\end{array}$ & $\begin{array}{l}\text { After refining } \\
\text { and washing. }\end{array}$ & $\begin{array}{c}\% \text { by } \\
\text { volume. }\end{array}$ \\
\hline I $\ldots \ldots$. & 0.739 & 0.743 & 9.0 \\
\hline $2 \ldots \ldots$ & 0.729 & 0.735 & 8.2 \\
\hline $3 \ldots \ldots$ & 0.727 & 0.748 & 9.8 \\
\hline $4 \ldots \ldots$ & 0.737 & 0.754 & IO. I \\
\hline $5 \ldots \ldots$ & 0.730 & 0.749 & 10.6 \\
\hline $6 \ldots \ldots$ & 0.722 & 0.737 & 14.0 \\
\hline 7. & 0.731 & 0.742 & 16.2 \\
\hline 8. & 0.735 & 0.753 & 23.0 \\
\hline & 0.737 & 0.757 & 28.0 \\
\hline
\end{tabular}

their water-white color and sweet odor for 2 years and are now better in both respects than samples of commercial gasoline refined by concd. sulfuric acid and which have stood side by side with the above-mentioned unsaturated gasolines during this same period of time. In the case of oils which do give tars, the use of concd. acid appears to be necessary as the more dilute acid does not hold the tars in solution, as the concentrated acid does. Fair results are obtained by employing other refining agents, such as the anhydrous metallic chlorides (cf. Justice, Eng. patent No. 3572, February II, I9r4). Anhydrous aluminum chloride yields remarkable fine white gasolines and this result is to be attributed also to the ability of this substance to decompose sulfur compounds, organic acids, such as the naphthenic acids, etc. 
up to $55^{\circ}$ and under pressures of one to 35 atmospheres, by the usual method of agitating with sulfuric acid, sp. gr. 1.84. The highly unsaturated gasolines were treated successively with 2 to 4 portions of conc. acid, $5 \%$ by volume of the gasoline refined. No other constants were obtained on the gasolines noted in the following table, as at the time this work was done no investigation of the refining process was contemplated. We wish to express our indebtedness to Dr. C. W. Clark, who carried out the work noted in Table I.

On redistilling these refined gasolines, abundant evolution of sulfur dioxide was noticed and a large high boiling fraction was obtained. Thus, although the original gasoline had been carefully fractioned and nothing boiling over $150^{\circ}$ included, it was noticed that redistillation after refining yielded 15 to $30 \%$ boiling over $150^{\circ}$ and the dry point was not reached at $260^{\circ}$.

Effect of Relative Proportions of Acid and Oil on the Sulfur Content of the Refined Product.--An olefin mixture consisting of hexenes and boiling from 55 to $75^{\circ}$ and made from monochlorides boiling from 120 to $140^{\circ}$ was used in the following experiments. This hexene fraction had a specific gravity of 0.700 and a bromine absorption number of 182 . After thorough agitation with $85 \%$ sulfuric acid at io to $15^{\circ}$, the supernatant oils were drawn off, washed with alkali and water, and distilled, the sulfur dioxide evolved being neutralized by a standard caustic soda solution in a Peligot tube.

Tabie II.-Sulfur Dioxide in Rafined Haxene.

\begin{tabular}{|c|c|c|c|c|c|}
\hline Fixpt. & $\begin{array}{l}\text { Vol. oil. } \\
\text { Cc. }\end{array}$ & $\begin{array}{l}\text { Vol. } \mathrm{H}_{2} \mathrm{SO}_{4} \\
\mathrm{Ce} .\end{array}$ & $\begin{array}{c}\text { Vol. resid- } \\
\text { ual oil. }\end{array}$ & $\begin{array}{l}\text { G. } \mathrm{SO}_{2} \text { on } \\
\text { distillation. }\end{array}$ & (RO) ${ }_{2}^{\%} \mathrm{SO}_{2}$ \\
\hline I. & 50 & 25 & 32 & 0.284 & 4.9 \\
\hline $2 \ldots \ldots \ldots \ldots \ldots \ldots$ & 50 & 50 & 28 & 0.146 & 2.9 \\
\hline $3 \ldots \ldots \ldots \ldots \ldots \ldots$ & 50 & 100 & 26 & 0.094 & I. 8 \\
\hline
\end{tabular}

That the concentration of the acid employed has a marked influence on the amount of sulfur dioxide in the refined and distilled oils has been shown by Hirsch. ${ }^{1}$

A number of samples of cracked gasoline were treated with acid in the usual way to determine approximately the per cent. of the oil polymerized to oils boiling higher than the upper boiling point limit of the original samples, which was $150^{\circ}$.

A series of experiments was carried out to determine the effect of varying concentrations of sulfuric acid on the formation of alcohols, or rather the per cent. of alcohols capable of being isolated from the final reaction products. The olefin employed was a mixture of amylenes and hexenes obtained as a minor product in the conversion of crude monochloropentane into the acetate by heating under pressure with sodium acetate

${ }^{1}$ Cf. Gurwitsch, "Wiss. Grundl. d. Erdötbearbeitung," p. 190. 
Table III,-Ehfect of Refining Cracked Gasolines Distilling beiow i $50^{\circ}$ on Distillation-Range of the Refined Product.

\begin{tabular}{|c|c|c|c|c|c|}
\hline No. & $\begin{array}{l}\text { Sp. gr. of } \\
\text { original } \\
\text { gasoline. }\end{array}$ & $\begin{array}{l}\text { Loss to } \\
\text { acid; \% } \\
\text { by volume. }\end{array}$ & $\begin{array}{l}\% \text { distil- } \\
\text { late below } \\
150^{\circ} \text { in } \% \\
\text { by vol. of } \\
\text { orig. gasol. }\end{array}$ & $\begin{array}{l}\% \text { distillate } \\
\text { above } 150^{\circ} \text { in } \\
\% \text { by vol of } \\
\text { orig. gasoline. }\end{array}$ & Remarks. \\
\hline $1 \ldots \ldots$ & 0.728 & $15 \cdot 3$ & 52.7 & 30.0 & \\
\hline $2 \ldots \ldots$ & 0.737 & 24.5 & 55.1 & 18.4 & \\
\hline $3 \ldots \ldots$ & 0.735 & I6.I & 62.3 & 19.6 & \\
\hline $4 \ldots \ldots$ & 0.738 & 27.5 & 33.9 & 36.6 & $\begin{array}{l}\text { From kerosene in tubes at } \\
550^{\circ} \text {. }\end{array}$ \\
\hline $5 \ldots \ldots$ & 0.740 & 48.0 & 23.2 & 27.8 & $\begin{array}{l}\text { From kerosene over nickel } \\
\text { at } 550^{\circ} .7 .8 \% \text { refined } \\
\text { product distilling above } \\
260^{\circ} \text {. }\end{array}$ \\
\hline $6 \ldots \ldots$ & 0.738 & 49.0 & $26 . I$ & 24.2 & $\begin{array}{l}\text { From kerosene over nickel } \\
\text { at } 550^{\circ} \text {. }\end{array}$ \\
\hline
\end{tabular}

in acetic acid. It contained a small per cent. of saturated hydrocarbons, indicated by the low iodine number I33, but for the purpose of comparing, the so-called hydrating effect of the acid gave sufficiently indicative results. Wischnegradski ${ }^{1}$ employed 2 volumes of acid, $50 \% \mathrm{H}_{2} \mathrm{SO}_{4}$, to one of amylene, b. p. 22-45. We have had little success with acid in concentrations as low as this, in fact we have obtained best results with $85 \%$ acid. Also, with respect to temperature, we have found that, in nearly all cases, including pure olefins of the various types up to duodecene, the reaction is very slow below $0^{\circ}$.

TABle IV.-Additron of WaTER to AMYLENE-HEXeNE MIXTURE BY SULFURIC ACID of VARYING CONCENTRATIONS.

\begin{tabular}{|c|c|c|c|c|c|c|c|}
\hline $\begin{array}{l}\text { Expt. } \\
\text { No. }\end{array}$ & $\begin{array}{c}\text { Conc. } \\
\text { of acid, } \\
\% \mathrm{H}_{3} \mathrm{SO}_{4} .\end{array}$ & $\begin{array}{l}\text { Reaction } \\
\text { tempera- } \\
\text { ture } 0^{\circ} \text {. }\end{array}$ & $\begin{array}{c}\text { Hours } \\
\text { agitated. }\end{array}$ & $\begin{array}{l}\text { Alcohol } \\
\text { fraction } \\
\text { of pptd. } \\
\text { oil, \%. }\end{array}$ & $\begin{array}{l}\text { Unchanged } \\
\text { hydrocar- } \\
\text { bons, \%. }\end{array}$ & $\begin{array}{c}\text { Loss as } \\
\text { sulfuric } \\
\text { esters and } \\
\text { vaporization. }\end{array}$ & Polymers, \\
\hline I....... & 50 & $-5^{\circ}$ & 2 & I & 90 & I & 8 \\
\hline $2 \ldots \ldots \ldots$ & 75 & $0^{\circ}$ & 3 & I 8 & 45 & I6 & 2 I \\
\hline $3 \ldots \ldots$ & 75 & $-10^{\circ}$ & 2 & 16 & 54 & 17 & 13 \\
\hline $4 \ldots \ldots$ & 75 & $0^{\circ}$ & 2 & 10 & 67 & 9 & I 4 \\
\hline $\begin{array}{l}5 \ldots \ldots \\
\quad 2 \text { vol. aci }\end{array}$ & 75 & $0^{\circ}$ & 2.5 & 10 & 57 & 15 & 18 \\
\hline $6 \ldots \ldots$ & 75 & $-15^{\circ}$ & 2 & 10 & 70 & I 2 & 8 \\
\hline $7 \ldots \ldots \ldots$ & 85 & $-15^{\circ}$ & 2.5 & 22 & 32 & I4 & 32 \\
\hline $\begin{array}{r}8 \ldots \ldots 8 \\
\text { acetic aci }\end{array}$ & + I vol. & $-10^{\circ}$ & 2.5 & 13 & 56 & 18 & 13 \\
\hline $9 \ldots \ldots$ & 95 & $-5^{\circ}$ & 2 & 4 & 5 & I I & 75 \\
\hline
\end{tabular}

When Expts. 2 and 4 are compared it will be seen that increased reaction time results in a larger yield of polymers and less alcohol.

From the work described above, it is obvious that large losses occur when highly cracked oils are treated with sulfuric acid in the usual manner and that the refined product contains high boiling polymers, and this too,

I Ann., 190, 328 (1877). 
when the presence in gasoline of high boiling heavy oil, even kerosene, is commonly considered objectionable. The refining of cracked gasolines constitutes a special refining problem. The foul odor of cracked gasoline is however not due to olefins, but to sulfur compounds, nitrogen bases and traces of naphthenic acids, as we have previously pointed out. Diolefins are probably the cause of the resinification which has been observed when highly cracked gasolines are permitted to stand in storage for several months. We find that very sweet, stable gasolines may be made by treating with a small quantity, not over $6 \%$ by weight of 85 to $90 \%$ sulfuric acid, followed by washing with alkali in the usual manner and redistilling. This method of operating is sufficient to remove thoroughly the most reactive and objectionable constituents, $i$. e., taror resin-forming diolefins and the malodorous compounds. Hall accomplishes the same object by distillation through Fullers earth, and Justice ${ }^{1}$ seeks to attain the same result by milder polymerizing agents, $i$. e., metallic chlorides such as zinc chloride or ferric chloride.

We believe, in the interest of conserving gasoline, the shortage of which will undoubtedly grow more acute, that the old sulfuric acid methods of refining should be discarded or modified, even if standards of quality heretofore the rule have to be modified and based solely upon efficiency during use.

The Presence of Alcohols in Petroleum "Acid Oils."-The odor of the highly aromatic fluid acid oils, regularly obtained as a refinery by-product, is mainly that of a mixture of secondary and tertiary alcohols derived from olefins, the amylenes to about duodecene, since the olefins above $\mathrm{C}_{12} \mathrm{H}_{24}$ in the series yield polymers almost exclusively. The odor of an artificial mixture made up of a number of these alcohols could not be distinguished from a sample of acid oil, washed neutral, from a petroleum refinery.

The actual demonstration of the presence of alcohols in acid oils obtained in refinery practice presented some difficulties owing to the large number of substances present, the wide range of distillation temperatures, the fact that the tertiary alcohols practically are not capable of acetylation or reaction with phthalic anhydride, etc. However, we had fair success by making use of the insolubility of the sodium alcoholates in a solution containing considerable dry ether. One kg. of light fluid acid vil recovered from the refining of cracked kerosene derived from a heavy Mexican crude petroleum was distilled with steam, thus obtaining about $750 \mathrm{~g}$. as a light yellow highly aromatic oil, divided, as collected, into 3 fractions. This was thoroughly dried by fused potassium carbonate and diluted with an equal volume of dry ether. After adding sodium wire, the solution was gently boiled under a return condenser. The : Ling. Pat 3572,$1934 ;$ y. Suc Chem lid , 34, $600+(1915)$. 
alcoholates were removed by filtering with suction, washed with dry ether and decomposed by water. The weight of the alcoholates totaled approximately $83 \mathrm{~g}$. The odor of the alcohols strongly suggested the presence of secondary alcohols and in fact after acetylating with acetic anhydride, all three fractions possessed pleasant fruity ester odors. The saponification values however showed that a considerable portion had been converted into hydrocarbons. On attempting to distil a small portion of the first fraction to determine the boiling point range, decomposition with formation of water was observed. One gram of the acetylated last fraction, sp. gr. 0.912, showed a saponification number of $\mathrm{I}_{42}$, and since decyl acetate has the saponification number $28 \mathrm{o}$, it is apparent that considerable decomposition of the alcohols originally present occurred during acetylation.

From the alkaline aqueous solutions obtained as noted above, $5.5 \mathrm{~g}$. of naphthenic acids were obtained. This naphthenic acid portion was converted into the methylester and then showed a boiling point above $225^{\circ}$, indicating more than 8 carbon atoms in the acids, and a saponification value of 246. The value calculated for $\mathrm{C}_{10} \mathrm{H}_{19} \mathrm{CO}_{2} \mathrm{CH}_{3}$ is 248. This close agreement may be only a coincidence and without particular significance. Sometime ago we isolated, in a similar manner, a small quantity of naphthenic acid from the gasoline fraction of this same Mexican petroleum, and the methylester had a saponification value of 516 ; calculated for $\mathrm{C}_{5} \mathrm{H}_{9} \mathrm{CO}_{2} \mathrm{CH}_{3}$ is $49 \mathrm{I}$. The odor of these naphthenic acids is very close to that of the Russian acids, but the naphthenic acids washed from Texas oils are heavy, viscous and nearly odorless. ${ }^{1}$ Gurwitsch $^{2}$ has pointed out that naphthenic acids are removed by conc. sulfuric acid from petroleum oils to a degree of completion far in excess of any result which can be calculated on the basis of partition coefficients. Since the naphthenic acids of the Mexican and Texas oils have not been described and apparently not studied, we feel justified in thus briefly calling attention to their presence in these oils.

The Refining of Crude Benzols.-Crude benzols from coal-gas tar, carbureted water-gas tar, or "holder oil" and Pintsch gas "hydrocarbon drips" are noted for the relatively large per cent. of so-called unsaturated paraffins which they contain. After treating such benzols with sulfuric acid, and washing neutral with alkali, it is always noted that on redistilling the treated oil, large quantities of sulfur dioxide are evolved, accomparied by blackening of the still residues. These still residues are highboiling viscous oils which on prolonged heating are convertible into pitch or resin, which some manufacturers erroneously designate as "coumarone

${ }^{3}$ In our opinion the practically odorless naphthenic acids from Texas oils merit consideration for many industrial applications in the form of their soaps.

2 Z. physik. Chem., 87, 323 (1914); Zaloziecki, Chem. Ztg., 16, 905 (1892). 
resin." It is much more probable that they are highly polymerized products derived in part from cyclopentadiene and similar diolefin hydrocarbons.

The sulfur dioxide evolved during redistillation is derived from the decomposition of neutral sulfuric acid esters, the formation of which was noted above in the case of cracked gasolines. That the amount of sulfur dioxide evolved bears a certain relation to the relative amount of sulfuric acid employed in refining is shown in the following table. An increase in the specific gravity after refining may also be noticed.

Table V.-Refining of Crude Benzols with Varying Amounts of Sulfuric Acid.

\begin{tabular}{|c|c|c|c|c|}
\hline \multirow[b]{2}{*}{ Kind of oil. } & \multirow{2}{*}{$\begin{array}{l}\text { Ratio; vol. } \\
\text { oil to acid. }\end{array}$} & \multicolumn{2}{|c|}{$\mathrm{D}_{4}^{20}$. } & \multirow{2}{*}{$\begin{array}{l}\mathrm{G} . \mathrm{SO}_{2} \text { evolved } \\
\text { per liter oil } \\
\text { on redistillation. }\end{array}$} \\
\hline & & Orig. & After treating. & \\
\hline Crude benzol. & $100: 25$ & 0.860 & 0.865 & 0.024 \\
\hline Crude benzol. ........ & $100: 12.5$ & 0.860 & 0.865 & 0.364 \\
\hline Crude benzol. .......... & 100: 7 & 0.860 & 0.866 & 0.480 \\
\hline Crude solvent naphtha . . & $100: 25$ & 0.864 & 0.869 & 0.384 \\
\hline Crude solvent naphtha & I00: 7 & 0.864 & 0.870 & 0.779 \\
\hline Crude benzol Pintsch. & $100: 12.5$ & 0.845 & 0.880 & $0.75 \mathrm{I}$ \\
\hline Crude benzol Pintsch. & I00: 7 & 0.845 & 0.882 & 2.064 \\
\hline
\end{tabular}

Although the fact that high boiling residues are obtained by refining crude benzols rich in unsaturated hydrocarbons is more or less familiar to every one engaged in the practice, the common acceptance of the erroneous idea that the loss to conc. sulfuric acid is a measure of the volume per cent. of unsaturated aliphatic hydrocarbon present, makes it desirable to point out again that, as in the case of unsaturated gasolines, the polymerized hydrocarbons remain dissolved in the oil layer. The "loss" only respresents that portion of the unsaturated hydrocarbons which forms water-soluble sulfuric acid esters, alcohols, tar and loss by emulsion.

The following results were obtained by refining a crude benzol from carbureted water-gas tar. ${ }^{1}$ It will be noted that the loss due to treating

1 An interesting case has recently come to our notice, in which a manufactured lot of so-calied C. P. benzol and C. P. toluol, made from carbureted water-gas tar, changed considerably on standing.

When freshly distilled, the benzol and toluol distilled from "first drop" to "dry point" well within the 2-degree limit commonly specified for these products. After storage for 4 months in clean metal drums, the distillation range was approximately $10^{\circ}$. A small part, not more than $1.5 \%$ of higher boiling oil was observed, although the first drop temperature was unchanged. This is due to the fact that part of the olefins originally present had escaped removal in the form of soluble sulfuric acid esters or by conversion into high boiling polymers, and had slowly polymerized, perhaps assisted by a trace of acid or metallic salts. Such deterioration is not noticed in the case of benzol and toluol made at high temperatures, as in by-product coke ovens, and relatively free from olefins, or even in benzol recovered from oil gas when the refining is carefully carried out with a much larger proportion of acid than is employed for good by-product benzol. 
with 0.1 volume of sulfuric acid is a little more than equalled by the $\%$ of high boiling polymers found in the residue boiling above $155^{\circ}$.

TABLE VI.

\begin{tabular}{|c|c|c|}
\hline & $\begin{array}{l}\text { I. Original } \\
\text { crude benzol. }\end{array}$ & $\begin{array}{l}\text { II. Product } \\
\text { of refining I }\end{array}$ \\
\hline $\mathrm{D}_{4}^{20^{\circ} \ldots}$ & 0.856 & 0.878 \\
\hline 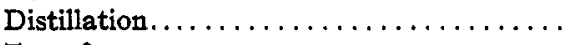 & $\%$ & $\%$ \\
\hline To $75^{\circ} \ldots \ldots \ldots \ldots \ldots \ldots \ldots \ldots \ldots \ldots \ldots \ldots$ & $5 \cdot 5$ & 5.0 \\
\hline $75^{-85^{\circ}} \ldots \ldots \ldots \ldots \ldots \ldots \ldots \ldots \ldots \ldots \ldots \ldots$ & 14.5 & $4 \cdot 5$ \\
\hline $85^{-} 95^{\circ} \ldots \ldots \ldots \ldots \ldots \ldots \ldots \ldots \ldots \ldots \ldots$ & $34 \cdot 5$ & $44 \cdot 5$ \\
\hline $95-105^{\circ} \ldots \ldots \ldots \ldots \ldots \ldots \ldots \ldots \ldots \ldots$ & 19.0 & 13.8 \\
\hline $105-115^{\circ} \ldots \ldots \ldots \ldots \ldots \ldots \ldots \ldots \ldots \ldots$ & $7 \cdot 7$ & 5.0 \\
\hline $115-125^{\circ} \ldots \ldots \ldots \ldots \ldots \ldots \ldots \ldots \ldots \ldots$ & 3.8 & 2.5 \\
\hline $125-135^{\circ} \ldots \ldots \ldots \ldots \ldots \ldots \ldots \ldots \ldots \ldots \ldots \ldots$ & 3.6 & 2.0 \\
\hline$I_{35}-145^{\circ} \ldots \ldots \ldots \ldots \ldots \ldots \ldots \ldots \ldots \ldots$ & 3.5 & I. 8 \\
\hline $145^{-155^{\circ} \ldots \ldots \ldots \ldots \ldots \ldots \ldots \ldots \ldots \ldots \ldots \ldots \ldots \ldots \ldots \ldots}$ & 2.0 & 1.7 \\
\hline Residue. . & 6.0 & 18.0 \\
\hline Loss on refining. & 10.2 & \\
\hline
\end{tabular}

Tars.-As pointed out above, none of the pure, unsaturated aliphatic hydrocarbons yield tars when treated with $85 \%$ or $94 \%$ sulfuric acid at I $5^{\circ}$. With the crude benzols, however, containing as high as $85 \%$ benzol and its homologs, the development of heat on treating with conc. sulfuric acid is sometimes so great that it is difficult to control the temperature of the reaction mixture within this limit. This energetic reaction with sulfuric acid has been previously noted with certain diolefins, particularly the conjugated diolefins, and such hydrocarbons have been noted in crude benzols by Armstrong ${ }^{1}$ and others.

We have noted tar formation with great liberation of heat, charring, etc., when treating the diolefins, myrcene and the diolefins made from linseed oil by destructive distillation of the calcium soap.

Cyclohexadiene ${ }^{2}$ and cyclopentadiene ${ }^{3}$ give tars instantly when treated with sulfuric acid. We believe the conclusion is warranted, therefore, that the tars sometimes noted in refining gasolines and kerosenes made by "cracking" are due to the presence of diolefins. Also, in view of the fact that the mono-unsaturated hydrocarbons, whose physical properties place them with the lubricating oils, $i$. e., of about 24 or more carbon atoms, are much less reactive toward sulfuric acid than those of lower molecular weight proves that the tars invariably obtained when crude lubricating oils are refined with sulfuric acid are not due to simple olefins. The sludge tars from lubricating oil are formed from diolefines or perhaps other substances. Our knowledge of the real nature of the hydro-

1 J. Soc. Chem. Ind., 3, 462 (1884).

2 Baeyer, Ann., 278, 88 (1894).

${ }^{3}$ Kramer and Spilker, Ber., 23, 3283 (I89o); 29, 552 (1896). 
carbons, nitrogen bases, naphthenic acids, sulfur compounds, etc., occurring in crude lubricating oil distillates, is so extremely meager that almost nothing positive can be said as to the nature of these tars.

Quantitative Determination of Olefins.--According to the findings recorded in the present paper, together with other facts previously well established, it can be said that at present there is no method for the quantitative determination of the per cent. by volume of unsaturated hydrocarbons in petroleum oils. In the case of crude benzols, an approximation can be arrived at by thorough agitation with cold sulfuric acid, washing and neutralizing as usual, distilling and adding the amount of the polymerized heavy residue to the loss during refining. The volume of the heavy polymerized residue, plus the loss to the acid, equals approximately the volume per cent. of olefins originally present. The commercial practice of manufacturing c. P. benzol and toluol is substantially this series of operations. It is obvious that the chief source of error in such an analytical method lies in the fact that redistillation of a fraction collected up to a certain degree of temperature will always yield in a second distillation a small residue, boiling above the original upper limit of temperature. It is also obvious that any method for the separation of the unsaturated hydrocarbons which is based on solubility differences, must be exceedingly inaccurate. Thus the liquid sulfur dioxide refining method of Edeleanu employed, as an analytical method gives only very rough values, invariably too high in the case of gasolines and is not applicable at all to crude benzols or other distillates containing any considerable \% of benzol hydrocarbons, owing to the great solubility of the aromatic hydrocarbons in this solvent. ${ }^{1}$ As has been already pointed out, fuming sulfuric acid attacks saturated paraffin hydrocarbons to a very marked degree.

Although the method of determining unsaturated hydrocarbons, as originally proposed by Krämer and Böttcher, specified the employment of fuming sulfuric acid, the method as now usually described refers only to ordinary acid. ${ }^{2}$

NEW YORK, N. Y.

${ }^{1}$ Under the influence of light and heat, sulfur dioxide combines with olefins, forming hard, amorphous substances. Thus butylene forms a substance of the composition $\left(\mathrm{C}_{4} \mathrm{H}_{3} \mathrm{SO}_{2}\right)_{n}$. Cf. Mathews and Elder, J. Soc. Chem. Ind., 22, 670 (1913).

2 "The method consists in shaking $25 \mathrm{cc}$. of the crude petroleum with $25 \mathrm{cc}$. of sulfuric acid of the specific gravity 1.83 , corresponding to ordinary strong sulfuric acid, about the equivalent of that used in petroleum refining. The acid and oil are shaken in a small flask with a long neck, the neck holding $25 \mathrm{cc}$. The flask is then filled with strong sulfuric acid until the oil which remains uncombined with the acid can be measured in the neck of the flask. The loss in volume between the original $25 \mathrm{cc}$. and the oil which remains undissolved by sulfuric acid is taken to represent the unsaturated hydrocarbons." Bacon and Hamor, "The American Petroleum Industry," I, 126 .

Egloff in a recent paper on the analysis of light oils also employs $95 \%$ sulfuric 